Research Article

\title{
Seismic Behavior of Innovative Precast Superimposed Concrete Shear Walls with Spiral Hoop and Bolted Steel Connections
}

\author{
Xi Wu $\mathbb{D}^{1},{ }^{1,2}$ Meng-fu Wang $\mathbb{D}^{1,2}$ and Ze-long Liu $\mathbb{D}^{1,2}$ \\ ${ }^{1}$ College of Civil Engineering, Hunan University, Changsha 410082, China \\ ${ }^{2}$ Key Laboratory for Green \& Advanced Civil Engineering Materials and Application Technology of Hunan Province, \\ Changsha 410082, China
}

Correspondence should be addressed to Meng-fu Wang; wangmengfu@126.com

Received 7 February 2021; Accepted 29 April 2021; Published 17 May 2021

Academic Editor: Shiming Wang

Copyright (c) $2021 \mathrm{Xi} \mathrm{Wu}$ et al. This is an open access article distributed under the Creative Commons Attribution License, which permits unrestricted use, distribution, and reproduction in any medium, provided the original work is properly cited.

\begin{abstract}
Owing to the desirable bond strength and excellent workability, spiral hoop and bolted steel connectors are introduced to enhance the connecting performance of superimposed reinforced concrete shear wall (SRCSW) system. In order to investigate the seismic performance of SRCSWs, applying such connecting methods under flexure-shear interaction and flexural dominated status, two groups of precast (PC) specimens were constructed: one-story and two-story specimens. Seismic behavior in terms of crack patterns, load-displacement response, ductility, stiffness degradation, strain response, and deformation results of SRCSWs is evaluated by the quasistatic cyclic test. It is shown that the wall specimens with the proposed connectors exhibited similar failure mode to that of the cast-in-place (CIP) walls and possessed adequate seismic performance such as lateral resistance, ultimate drift ratio, and lateral stiffness besides the ease of erection. The strain responses and deformation results of the PC specimens under reversed cyclic loading were presented to evaluate the effectiveness of the introduced connections. The test results indicated that the PC walls adopting bolted steel connectors behaved better in force transmission and exhibited greater integrity characteristic compared with the specimens having spiral hoop connectors. Lastly, simplified finite element models considering the nonlinear slip behavior within the connection joint of SRCSWs were established and verified, which could provide sufficient accuracy and efficiency to predict the seismic response of the proposed wall system.
\end{abstract}

\section{Introduction}

Served as a semi-precast wall system, superimposed concrete shear wall is a combination of precast wall panel prefabricated at manufacturing plants and CIP concrete layer cast in construction site. With outstanding features such as environmental friendly, light in deadweight, the excellent feasibility for assembling, and the good working ability in coordinate, the SRCSW structures are prevailing in the trend of building industrialization in China. In the current construction practice, the SRCSW segments in upper and lower stories are connected by overlapping reinforcements conventionally, of which the longitudinal reinforcements are connected indirectly (as depicted in Figure 1(a)). With a certain anchorage length into the wall segments, the lap splicing rebar was embedded in the CIP layer. The embedded length of the longitudinal lap rebar is specified by relevant code to ensure that the bond strength and the spacing are equal to those of the vertical transverse rebar of the wall element. This wet-type connection joint is designed and constructed to emulate the CIP connection. After in situ assembling, the cavity of SRCSW is cast by concrete, forming an integrated shear wall. However, unexpected failures were reported by the previous seismic test on SRCSWs with conventional connection detailing. The in-plane rocking behavior attributed to the insufficient bond strength of traditional connections was observed when SRCSW was subjected to severe lateral force. In addition, shear slide in SRCSW specimen, constructed by lap spliced connecting method, is obviously concentrated at the wall-to-foundation 


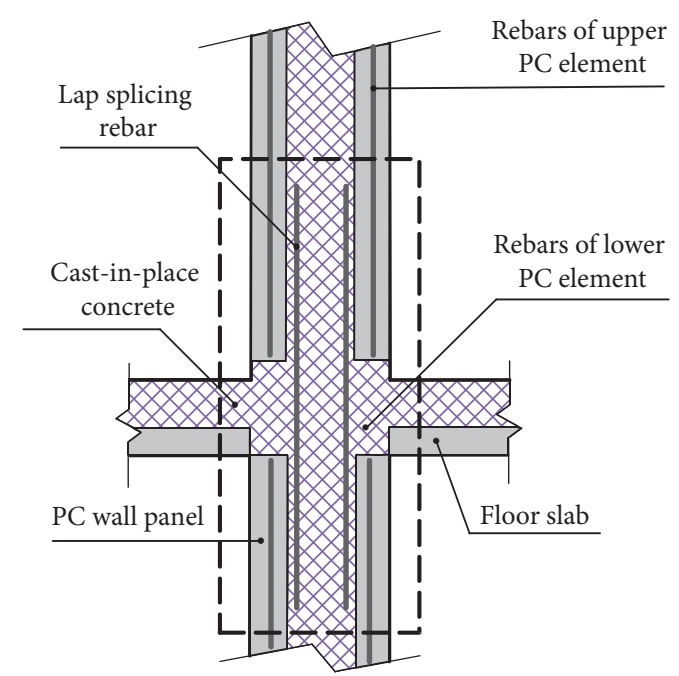

(a)

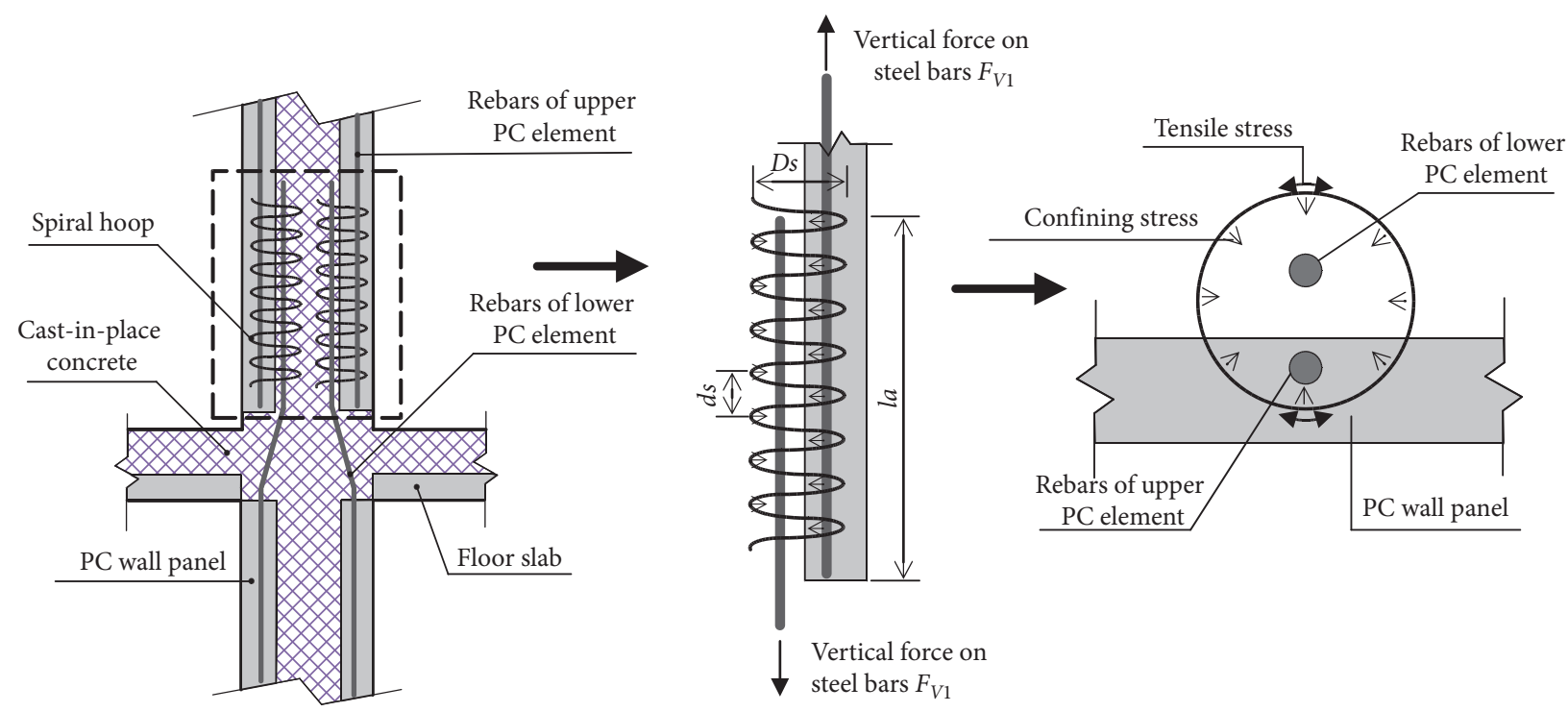

(b)
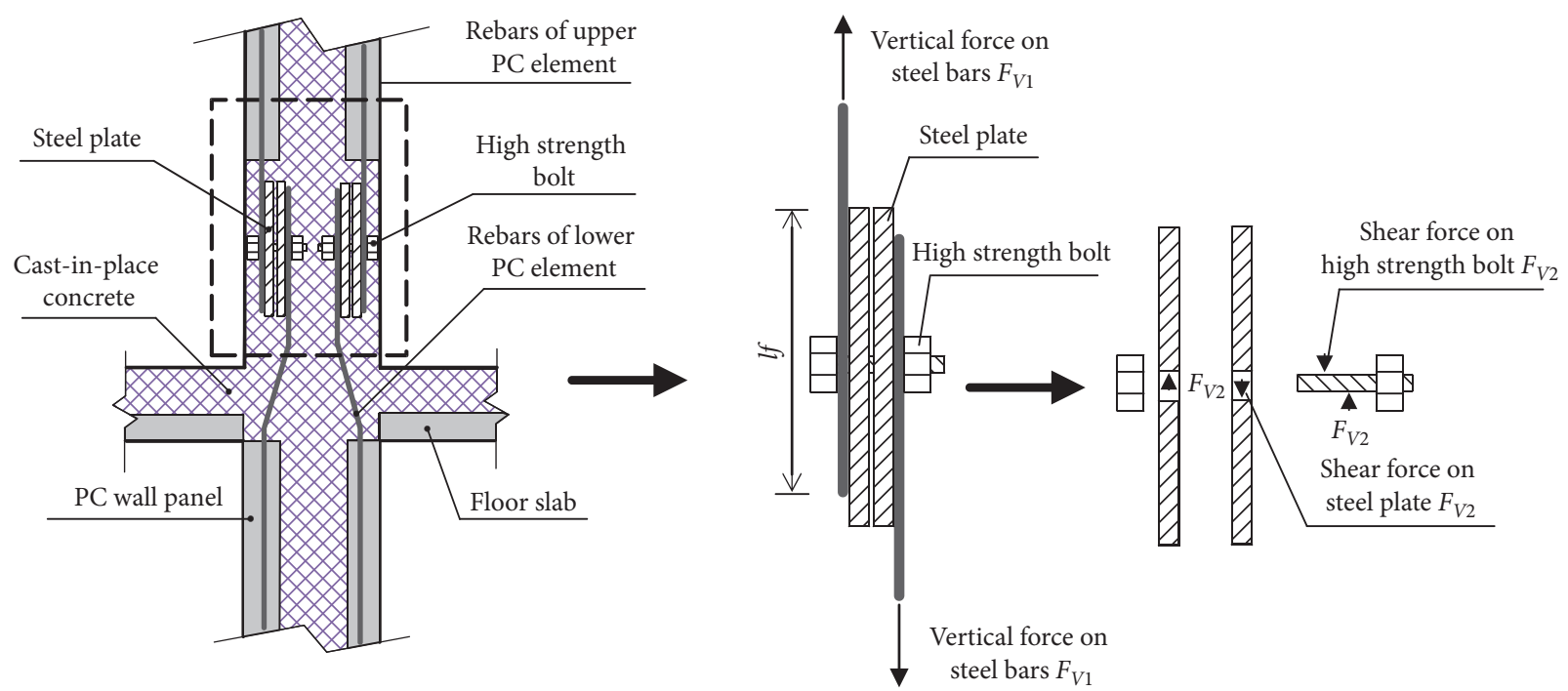

(c)

FIGURE 1: Schematic diagram of the connecting methods for SRCSW. (a) Lap splicing connector. (b) Spiral hoop connector. (c) Bolted steel connector. 
area, leading to a decrease in seismic resistance such as lateral stiffness and load bearing capacity [1]. The SRCSW system is mainly applied in nonseismic areas for its inadequate earthquake resistance.

In the last decades, numerous experimental and theoretical studies have been conducted to enhance the seismic behavior of PC structure, by means of application of novel structural system or modification of structural characteristics. Proposed by PRESSS program, unbonded posttensioned (UPT) concrete shear wall is a type of nonemulative PC structure, which could reduce shear slip and residual displacement abundantly at the wall-to-wall or wall-to-foundation interface, offering excellent restoring force during earthquake [2-4]. However, the poor energy dissipation and the demand for thicker wall size are the main imperfections in utilizing this novel wall system. Although some improvements have been made to increase energy dissipation of the UPT wall [5-9], complex technology and costly construction are still required. A number of researchers were devoted to enhancing the seismic performance of wall panel. Xiong et al. [10] tested PC walls with two-way hollow core; the postcast reinforced concrete in hollow core provided sufficient axial resistance even at a limit state and better energy accumulation comparing with the CIP wall. A new type of precast wall composed of hybrid braced rebars and foam board was proposed by Li et al. [11]. The test result indicates that the PC walls are lighter than CIP wall, but the seismic resistance is comparable. With the aim of reducing the slip at the wall-tofoundation joint and increasing the load bearing capacity, Wang et al. $[12,13]$ proposed an innovative PC wall by adding inclined steel bracing into the cavity of SRCSW, achieving favorable seismic performance under cyclic loading test.

As the recent earthquake events such as the L'Aquila (2009) earthquake in Italy [14] and the Canterbury (2011) earthquake in New Zealand [15] reported, earthquake damage is mainly concentrated at the connection area of PC structures. The overall connecting performance of connection joint, functioning as the transmission of both lateral and axial load in structural system, is the key issue for ensuring the earthquake resistance of PC structures. Plenty of studies were focused on the improvement of connection joint. Chong et al. [16] tried to reduce the rocking behavior and make the plastic region move upward by applying an enhanced horizontal joint in SRCSW panel. Soudki et al. [17] proposed five different types of mild steel connection joints for PC wall. Seismic behavior in terms of loading bearing capacity, stiffness degradation, ductility, and slip deformation of six specimens adopting these connection devices was compared under cyclic or monotonic loading test. Psycharis et al. [18] examined the seismic behavior of PC wall with wall shoe and steel plate connectors by quasistatic test. Han et al. [19] proposed a method of utilizing $\mathrm{H}$-shaped or I-shaped steel to connect precast wall segments, with the aim of reducing the gap opening generated at the wall base area. Sun et al. $[20,21]$ experimentally studied the cyclic behavior of precast shear wall with bolt-steel connections. Shen et al. [22] carried out cyclic load tests of a new type of PC wall connected by steel shear key, and the test result indicated that the proposed wall specimen exhibits satisfactory bearing capacity and deformability.
Currently, with outstanding bond strength and continuity in load transferring, grout sleeve, mechanical sleeve, and metal duct are prevailing as practical connecting methods for precast shear wall. These connection methods have been widely used in engineering practice for multistory buildings in seismic regions of America, New Zealand, Japan, and China [23-27]. By pouring high-strength mortar, grout sleeve is used to connect reinforcement for the integrated precast shear wall or precast frame structure. To obtain excellent bond strength, the full volume ratio of mortar in grout is required [28]. However, there are few solutions to detect the compactness, and it is difficult to guarantee the connection quality. Due to the limited thickness of prefabricate layer in SRCSW and the arrangement of minor diameter reinforcement, the metal duct and mechanical sleeve connectors, which require sufficient space for assemblage, are not fit for SRCSW system. Therefore, there is a need to improve the traditional indirect connection method to satisfy the demand for acceptable seismic behavior of SRCSW system in seismic areas.

Previous experimental research conducted by Hosseini and Rahman $[29,30]$ has shown that the bond behavior between rebar and grout enhanced significantly with spiral hoop connection. The continuous confining pressure provided by the circular spiral acts as uniform lateral fluid pressure surrounding the steel rebar. This form of connection joint is fit for connecting precast components because of its simplicity and convenience in construction as well as the economical convenience. In addition, it is acknowledged that connector consisting of steel plate and bolt is also a reliable connecting method. Welded to the connecting steel plate, axial and lateral force on the connecting reinforcements are transmitted directly through the bolted steel connector by frictional or squeezing action between bolt and steel plate $[19,20]$.

For the purpose of improving the seismic performance of SRCSW, the authors have developed an innovative SRCSW $[12,13]$. By arranging $\mathrm{X}$-shaped steel bracing into the cavity of SRCSW, enhancement of the seismic performances in terms of lateral resistance, energy dissipation, ductility as well as stiffness is achieved. Meanwhile, capitalizing on the advantages of the spiral hoop and bolted steel connectors, the two connection methods are introduced to improve the connecting performance of such innovative SRCSW system. The configuration and the working mechanism of the two proposed connectors are depicted in Figures 1(b) and 1(c). By conducting quasistatic test, seismic performance of one group of SRCSWs assembled with single wall panel element and another group assembled with two PC elements associated with interstory floor slab are evaluated and compared with that of CIP specimens. The workability and feasibility of the introduced connection joints are examined in this work.

\section{Experimental Program}

2.1. Wall Design and Construction. Curly fabricated by $\Phi 4$ ( $4 \mathrm{~mm}$ in diameter) steel wire, the spiral hoops spaced at $40 \mathrm{~mm}(d \mathrm{~s})$ are fixed to the longitudinal rebars on the bottom of the reinforcement mesh of PC wall element 
(marked with gray in Figure 1(b)). The spiral hoop is characterized by an aperture (Ds) of $50 \mathrm{~mm}$. After casting concrete, a small part of spiral hoop is embedded into the outer precast layer, and the remaining space of the aperture is set aside for the connecting rebar of the lower PC element. The lap distance $\left(l_{a}\right)$ of connecting reinforcement into the spiral hoop is set to be $450 \mathrm{~mm}$. When the assemblage of PC elements are finished, the concrete is cast in the cavity of SRCSW panel, and the connecting rebars and spiral hoop are formed into integrity. For the bolted steel connector, the longitudinal rebars are welded to a steel plate with a dimension of $750 \mathrm{~mm} \times 150 \mathrm{~mm} \times 4 \mathrm{~mm}$. The minimum length $\left(l_{f}\right)$ of fillet welding is $120 \mathrm{~mm}$ according to relevant specification [31], ensuring sufficient welding strength. Bolt holes with the diameter of $22 \mathrm{~mm}$ are positioned for the arrangement of M20 bolt when prepared for the manufacturing of PC panels. During the installation of PC elements, the upper and lower PC panels are connected by grade 10.9 bolts. After casting concrete in construction site, the steel connectors are embedded into concrete layer, as plotted in Figure 1(c).

The test specimens were divided into two groups. For group 1, single PC wall panel was assembled to the PC foundation, with the dimension of $1450 \mathrm{~mm} \times 1000 \mathrm{~mm} \times 160 \mathrm{~mm}$. For group 2, the PC specimens were assembled with two individual PC panels, linked by CIP floor slab. All specimens had $120 \mathrm{~mm} \times 560 \mathrm{~mm}$ CIP floor slab between upper and lower wall panel. The assembled PC panels were fabricated identically, with the dimension of $1450 \mathrm{~mm} \times 1400 \mathrm{~mm} \times 160 \mathrm{~mm}$. CIP specimens with the same dimensions as the PC specimens were set as benchmarks for each group, which were numbered SW1 and SW2, respectively. The PC specimens using spiral hoop connections were numbered SRCSW1-1 in group 1 and SRCSW2-1 in group 2. The PC specimens with bolted steel connectors were numbered SRCSW1-1 with single wall panel and SRCSW2-2 with two panels. The reinforcement detailing for each group is identical, as depicted in Figure 2. The vertical and horizontal distributed reinforcements of the wall panel section are $110 @ 150$ and $\Phi 10 @ 200$, respectively. Different from the lap splicing bars reserved for spiral hoops in SRCSW1-1 and SRCSW2-1, the longitudinal reinforcements of SRCSW2-1 and SRCSW2-2 were welded to the steel plate, by which the upper and lower PC elements were joined together. 4Ф12 and 6Ф12 act as boundary reinforcements for group 1 and group 2, respectively. Stirrup at the boundary column is fabricated by enclosed $\Phi 6$ rebar, spacing at $150 \mathrm{~mm}$.

As depicted in Figure 2, square notches located at the bottom of boundary column are designed for welding $\mathrm{X}$-shaped steel bracing and assembling boundary lap splicing rebars. Meanwhile, the notch areas at the wall bottom are supposed to be the plastic region for shear wall. Steel plates with the cross-section of $70 \mathrm{~mm} \times 4 \mathrm{~mm}$ are embedded into the cavity of PC panel, forming X-shaped steel bracing. The longitudinal reinforcements of boundary column are connected by lap splicing method, and the lap length is $450 \mathrm{~mm}$. All the wall panels are constructed with the identical thickness of $160 \mathrm{~mm}$, and the wall sections of
PC panel are designed based on $1: 2: 1$ principle. The foundation beam of PC specimens is prefabricated, with protruding bars above the foundation. RC loading beam with cross-sectional dimension of $350 \mathrm{~mm} \times 250 \mathrm{~mm}$ was cast at the top of all the specimens, through which the vertical and lateral force are transferred. Therefore, the spanshear ratio of group 1 is about 1.63 , while that of the other group is 2.28. Except that monolithic specimens SW1 and SW2 were cast entirely, the erection of a two-story PC specimen is constructed successively, and the main construction processes are summarized as follows: (a) constructing RC foundation beam detailed with double raw of protruding rebars, of which the longitudinal rebars were welded to the steel plate for the bolted steel connecting specimens; the lapped reinforcement of the boundary region and the wall web section were placed with the height of $450 \mathrm{~mm}$ above foundation beam; (b) adjusting the $1^{\text {st }} \mathrm{PC}$ panel to the RC foundation, inserting two branches of steel plates into the cavity of PC panel to form $X$-shaped steel bracing, and welding the $X$-shaped steel bracing to the steel insert located at the foundation beam; (c) casting the intermediate layer of the $1^{\text {st }}$ PC panel and the interstory floor slab; (d) assembling the $2^{\text {nd }}$ PC panel and welding the upper pair of X-shaped steel bracing to the lower one; (e) casting the intermediate layer of the $2^{\text {nd }}$ story PC panel and the loading beam. Figure 3 presents the photographs of SRCSW2-2 during the erection.

2.2. Materials. Self-compacting concrete (SCC) with a minimum strength grade of $\mathrm{C} 30$ was utilized to construct the test specimens. Maintained under the same experimental environment as the wall specimens, the cubic block derived from each course of casting concrete, with the dimension of $150 \mathrm{~mm} \times 150 \mathrm{~mm} \times 150 \mathrm{~mm}$, was tested prior to the test [32]. The measured cubic strength and the induced compressive strength of concrete are summarized in Table 1. Meanwhile, the mechanical properties of steel are obtained by tension test, as listed in Table 2 .

2.3. Loading Program. Figure 4 depicts a $500 \mathrm{kN}$ hydraulic actor with one end fixed to the stiff reaction wall and the other end bolted to the loading beam, by which lateral force was applied though the center of the loading beam. Axial load was applied by a $500 \mathrm{kN}$ hydraulic actor placed between the reaction frame and the loading beam. Load cell was arranged above the hydraulic jack to monitor the axial load. For the purpose of transferring the point axial load into line load, steel rigid beam was placed between hydraulic jack and loading beam. In order to simulate a completely fixed constraint, the foundation beam was prestressed by highstrength rods to the strong floor, and two horizontal jacks are placed at each side of foundation beam to prevent sliding of specimen during the loading procedure. To avoid out-ofplane behavior, four steel frame supports were pinned to the wall specimen.

The axial load was applied with the value of $F=0.1 f_{c} A$, where $f_{c}$ and $A$ stand for the compressive strength and the net cross-sectional area of the wall specimen, respectively. As 


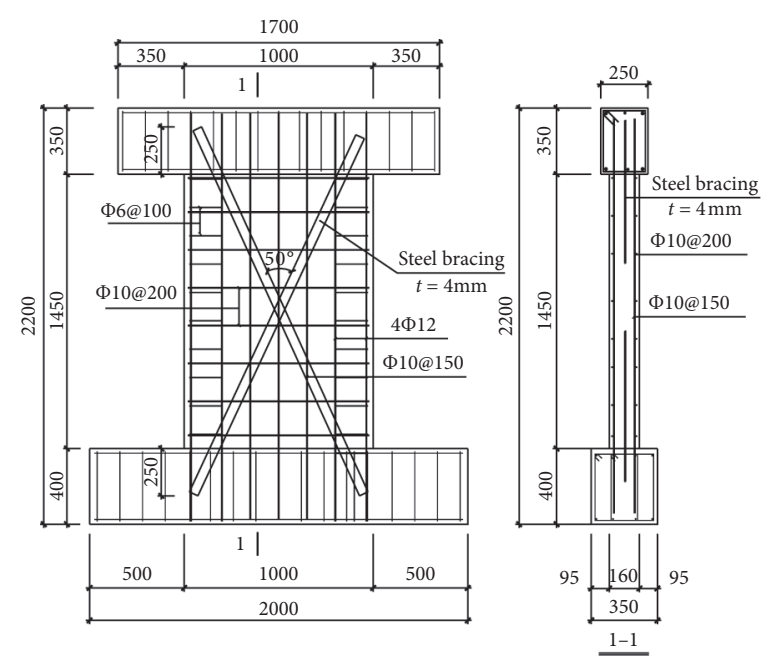

(a)

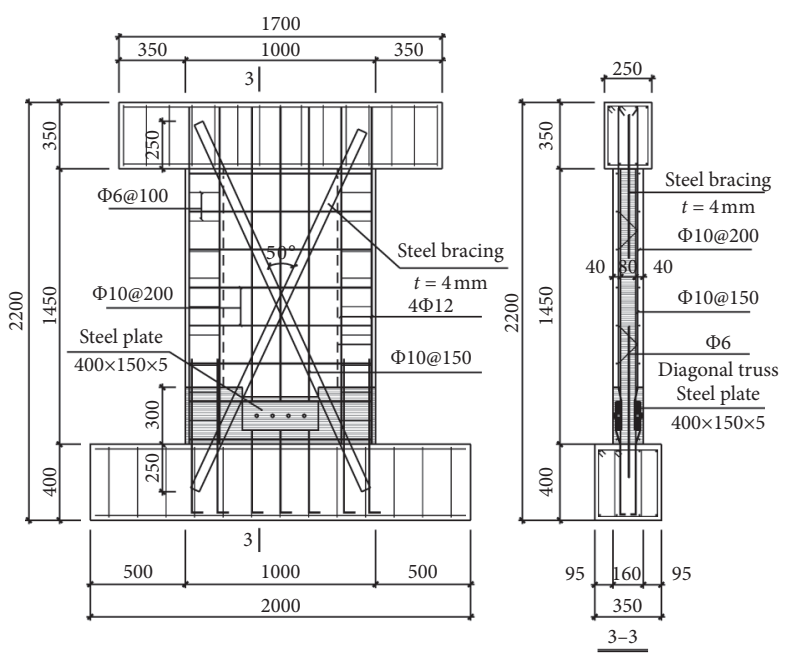

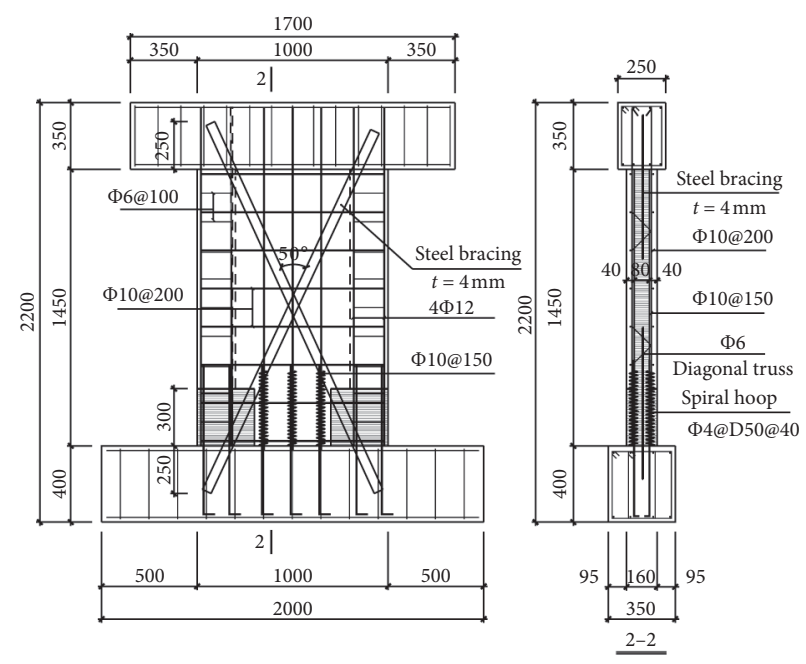

(b)

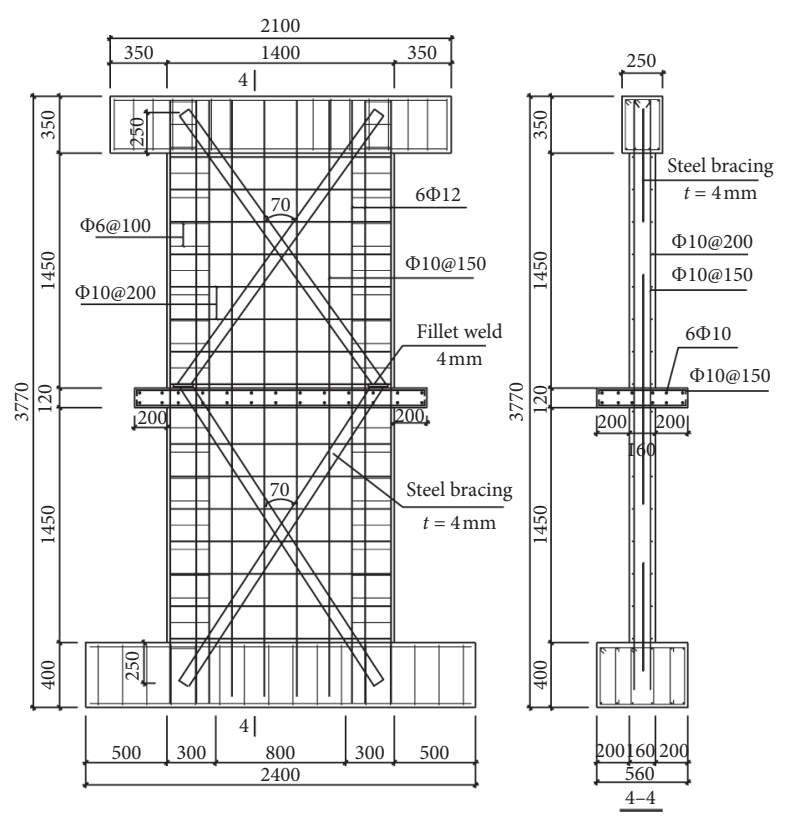

(d)

FIgURE 2: Continued. 


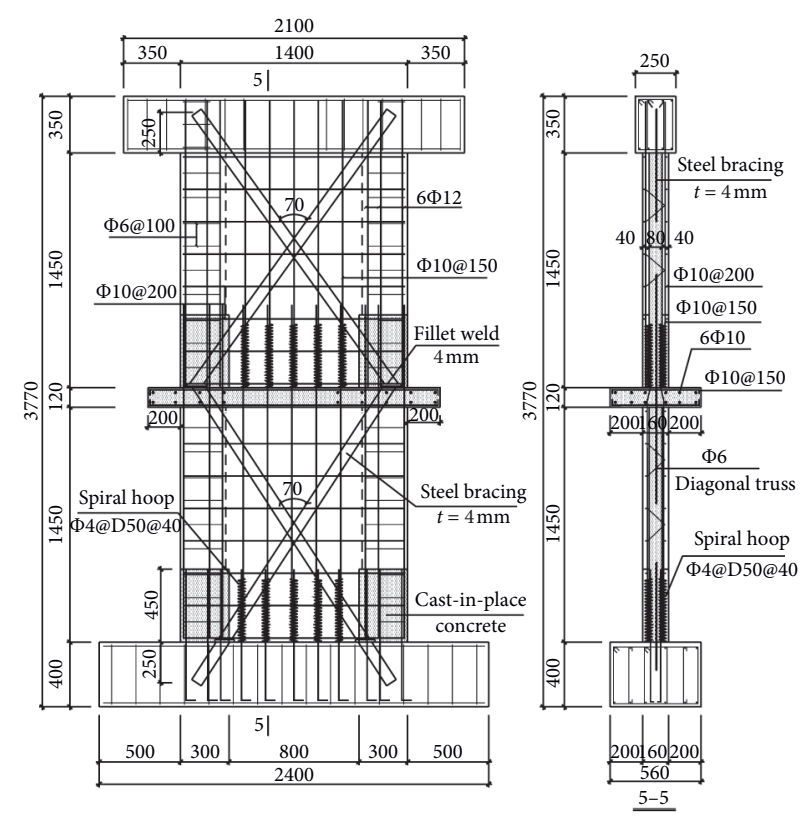

(e)

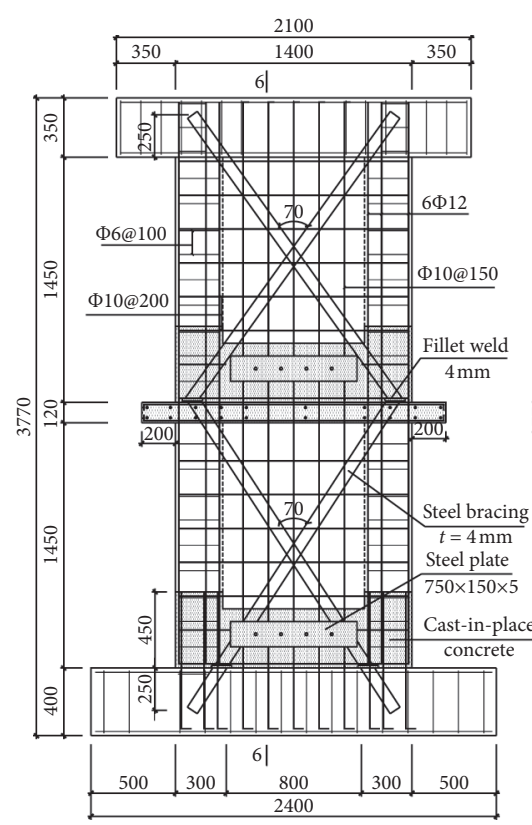

(f)

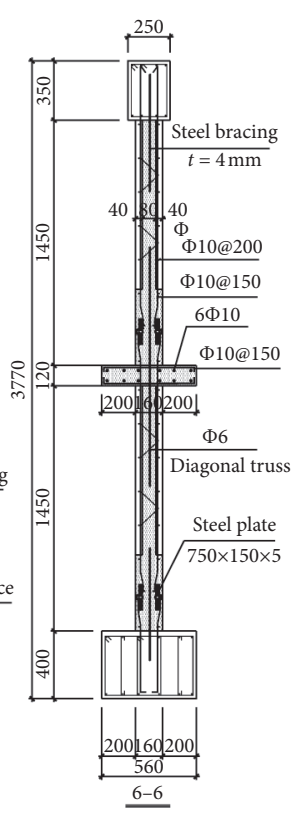

FIGURE 2: Geometry and reinforcement details of specimens (unit of mm). (a) SW1. (b) SRCSW1-1. (c) SRCSW1-2. (d) SW2. (e) SRCSW2-1. (f) SRCSW2-2.

for the lateral load protocol, the tests were controlled by displacement, and the corresponding displacement drift of each cycle is set to $1 / 3000,1 / 1500,1 / 1000,1 / 500,1 / 300,1 /$ $200,1 / 150,1 / 100,1 / 70,1 / 60,1 / 50$, and $1 / 40$. When the specimen reached the supposed displacement, the load test paused to record cracks and displacement data. The ultimate state of the test was defined as the strength of specimen dropped to $85 \%$ of its peak strength, at which time the test terminated.

2.4. Arrangement of Measuring Points. To monitor the displacement changes during the test, a series of displacement gauges were arranged, as depicted in Figure 5. Displacement gauge numbered D8 in group 1 was applied to monitor the displacement-controlled loading process. For the two-story specimens, D16, located at the center of floor slab, and D17, placed at the top of the $2^{\text {nd }}$ wall panel, were used to record the lateral displacement of the two stories. Hence, the story drift could be analyzed from the collected data of D16 and D17. To monitor the shear slide and rocking behavior of wall panels, a number of dial indicators were arranged at the wallto-foundation or wall-to-wall connection area. For instance, D4 was set for detecting the slide deformation of wall-tofoundation joint, and D1-D3 were equipped for monitoring the rocking behavior in group 1. Moreover, dial indicators located at the two ends and the side face of RC foundation were utilized for monitoring any rotation or slide deformation of specimens.

To investigate the strain response of connection joints and steel bracing, strain gauges were adhered to the reinforcement and steel plate before constructing wall specimens, as shown in Figure 6. Take the spiral hoop connector, for example; strain gauges were $50 \mathrm{~mm}$ above the top surface of footing beam or CIP floor slab, and the strain gauges of the upper PC component were arranged at the corresponding overlapping position. As for the bolted steel connectors, strain gauges were positioned $30 \mathrm{~mm}$ below the steel plate of the lower PC element and $30 \mathrm{~mm}$ above the corresponding steel plate of the upper PC panel.

\section{Results and Discussion}

3.1. Failure Modes and Observation. For better observation of the crack progressing, grids by $100 \mathrm{~mm} \times 100 \mathrm{~mm}$ were marked before the loading test, and the oblique lines representing the tracks of cracking are depicted in Figure 7. The test observations of the tested specimens can be summarized as follows.

3.1.1. Group 1. Set as the benchmark specimen, SW1 is cast in situ entirely. When the imposed displacement reached $2.0 \mathrm{~mm}$ (drift ratio $\theta=0.14 \%$ ), the first crack, due to the tensile stress developed by the moment surpassing the tensile strength of concrete, was recorded as flexural appearance at the height of $250 \mathrm{~mm}$ above the wall base. The corresponding lateral force at the crack point was $-165.3 \mathrm{kN}$ (pull direction) and $157.0 \mathrm{kN}$ (push direction). With the increasing of top displacement, more and more cracks were observed, initiated in the boundary area and then propagated into inclined shear crack to the center of the wall panel. The maximum load was documented with the values of $-345.5 \mathrm{kN}$ and $353.4 \mathrm{kN}$ when the top displacement reached $21.0 \mathrm{~mm}(\theta=1.44 \%)$. During the phase of $\theta=1.44 \% \sim$ $2.07 \%$, little new cracks occurred, the existing cracks became wider, and the cove concrete at the wall toe started spalling. At 

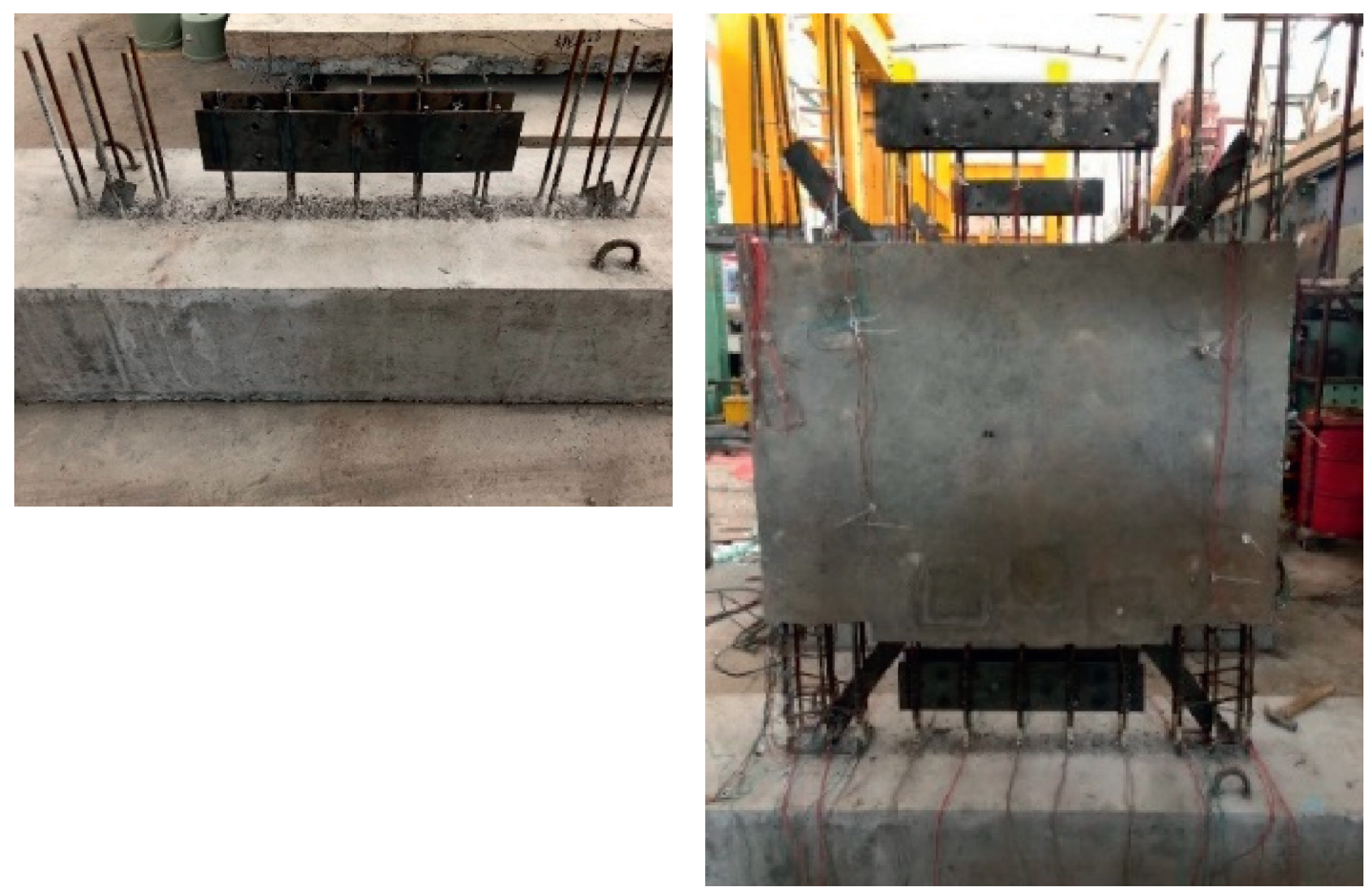

(a)

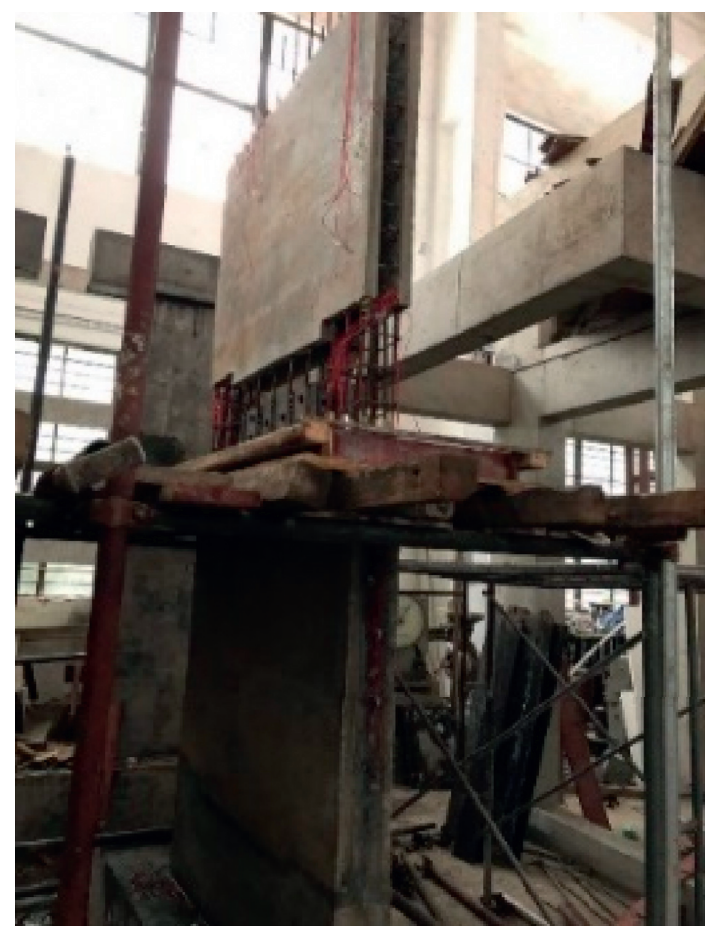

(c) (b)

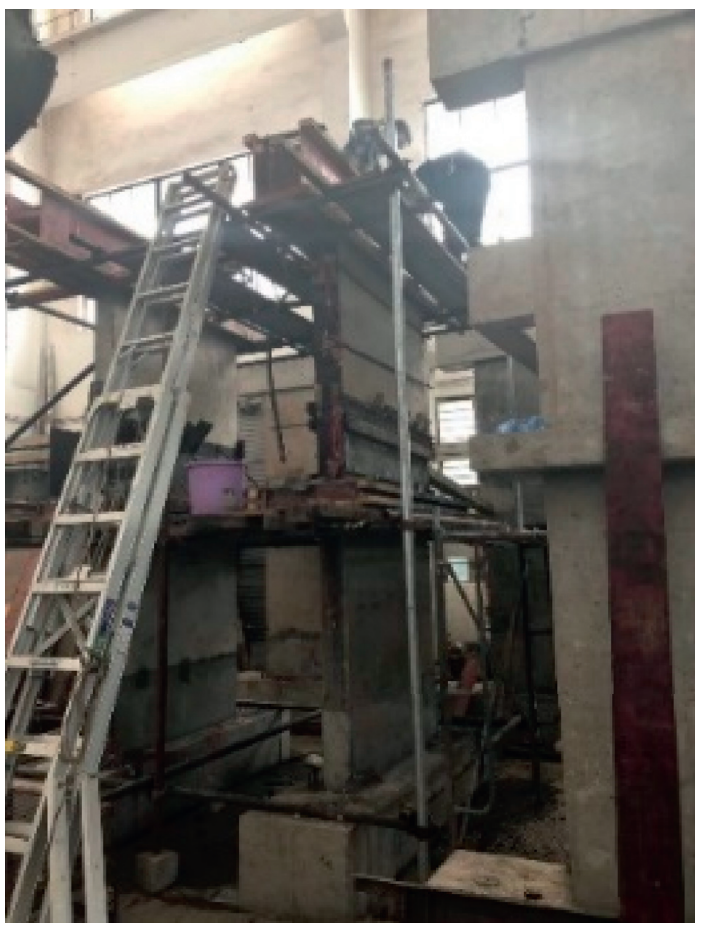

(d)

FIGURE 3: Photographs of fabricated shear wall specimen SRCSW2-2 during construction procedure. (a) Constructing base foundation. (b) Assembling PC wall segment of $1^{\text {st }}$ story. (c) Constructing floor slab and assembling PC wall segment of $2^{\text {nd }}$ story. (d) Casting the CIP layer of the $2^{\text {nd }}$ story together with the loading beam.

$2.07 \%$ drift, the specimen reached the damage state as the load bearing capacity dropped to $85 \%$ of the maximum strength, at which time severe concrete crushing and exposure of boundary rebar were observed. As the SSR of SW1 equaled 1.63, the specimen exhibited flexural-shear failure mode. The cracking pattern at the ultimate stage is shown in Figure 7(a).

For the PC specimen SRCSW1-1 with spiral hoop connection, the first horizontal crack was observed at the interface 
TABLE 1: Material properties of concrete.

\begin{tabular}{lcc}
\hline Specimen & Average cubic strength $f_{\text {cu }}(\mathrm{MPa})$ & Compressive strength $f_{\mathrm{c}}(\mathrm{MPa})$ \\
\hline SW1 & 37.5 & 28.5 \\
SRCSW1-1, SRCSW1-2 & 32.8 & 24.9 \\
SW2 & 30.8 & 23.4 \\
SRCSW2-1, SRCSW2-2 & 31.6 & 24.0 \\
\hline
\end{tabular}

TABLE 2: Measured strength of steel.

\begin{tabular}{lccc}
\hline Size & Position & $f_{\mathrm{y}}(\mathrm{MPa})$ & $f_{\mathrm{u}}(\mathrm{MPa})$ \\
\hline$\Phi 6$ & Boundary stirrup and diagonal truss & 385.7 & 533.2 \\
$\Phi 10$ & Longitudinal rebars & 466.3 & 634.2 \\
$\Phi 12$ & Boundary longitudinal rebar & 459.1 & 627.8 \\
$t=4 \mathrm{~mm}$ & Steel bracing & 262.2 & 421.1 \\
\hline
\end{tabular}

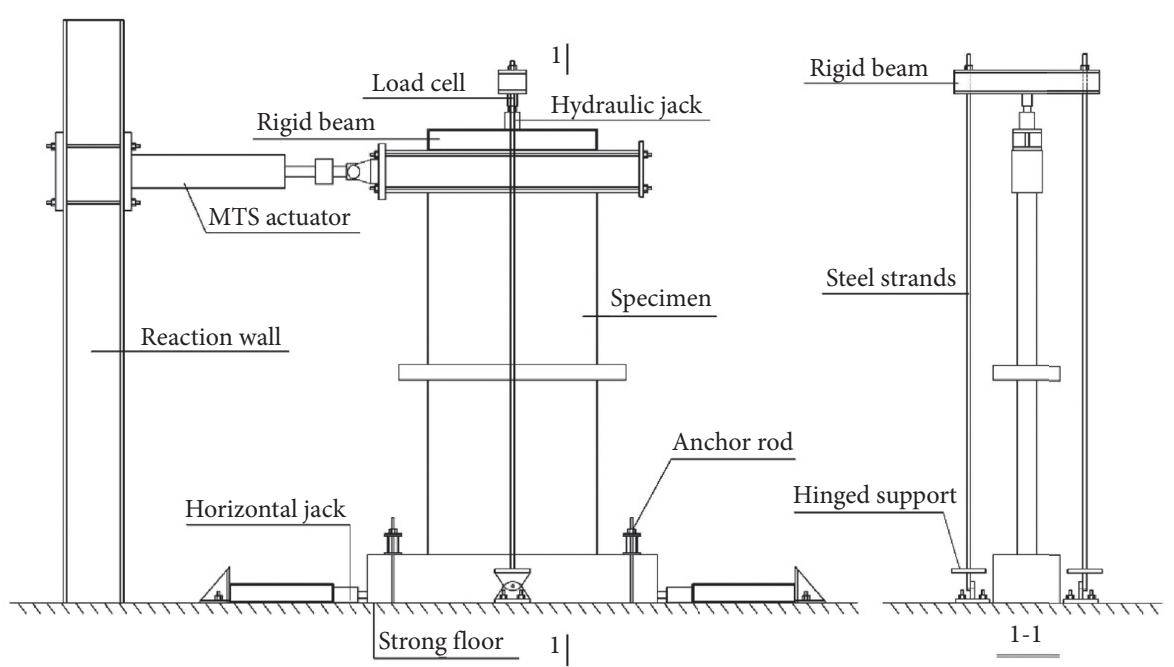

(a)

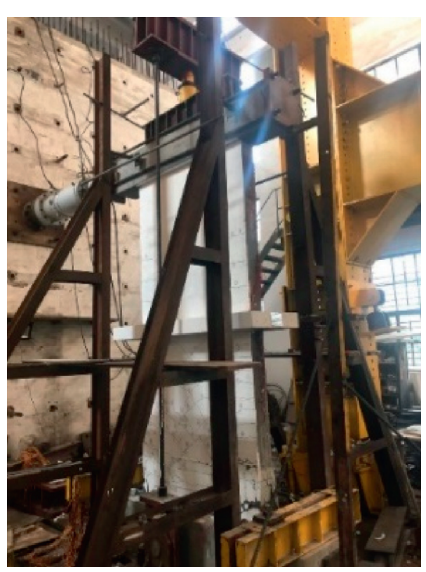

(b)

Figure 4: Test setup. (a) Schematic view. (b) Photograph.

between PC layer and the CIP square notch at the wall toe when the imposed displacement became $2.0 \mathrm{~mm}(\theta=0.14 \%)$. During the loading cycles between $2.0 \mathrm{~mm}$ and $21.0 \mathrm{~mm}$, several new flexural cracks occurred and developed downward the wall panel into inclined cracks. Meanwhile, the gap opening at the wall-to-foundation interface was observed. The width of the gap opening became larger with the increase of top displacement and was recorded with the maximum value of $4.0 \mathrm{~mm}$ during the test. SRCSW1-1 reached the peak resistance of $278.4 \mathrm{kN}$ when the top displacement reached the level of $21.0 \mathrm{~mm}$ $(\theta=1.44 \%)$, and the loading test ended when the imposed displacement reached $27.0 \mathrm{~mm}(\theta=1.90 \%)$. For the specimen SRCSW1-2 with bolted steel connection, horizontal crack was firstly recorded at $3.0 \mathrm{~mm}$ displacement level $(\theta=0.21 \%)$, at which point the lateral resistance was $-146.0 \mathrm{kN}$ and $147.8 \mathrm{kN}$, respectively. At $1.44 \%$ drift, the maximum loadbearing capacity was documented at a value of $310.7 \mathrm{kN}$ in the push direction, which is about $11 \%$ lower than the benchmark specimen SW1. The test ended at the top displacement of $30.0 \mathrm{~mm}(\theta=2.07 \%)$ when the lateral force decreased to $85 \%$ of the peak load.
3.1.2. Group 2. Specimen SW2 maintained an elastic state until the initial flexural crack occurred at the boundary column of $1^{\text {st }}$ story, at the height of $150 \mathrm{~mm}$ above the footing beam. The cracking load was recorded at a value of $90.7 \mathrm{kN}$ in positive direction, and the top displacement was record at $4.0 \mathrm{~mm}$. When loaded to $192.1 \mathrm{kN}$, the first flexural crack was observed in the second story. During the loading stage between $\theta=0.33 \%$ and $\theta=0.94 \%$, numerous new flexural cracks appeared and developed, extending from the edge of the boundary area to the center bottom of the wall. The outmost reinforcement at the boundary column was yielded at the top displacement of $30.0 \mathrm{~mm}(\theta=0.94 \%)$, and the specimen entered the plastic hardening stage. When the displacement reached $45.0 \mathrm{~mm}$, the specimen achieved the maximum lateral capacity of $324.6 \mathrm{kN}$. Followed by the vertical crack due to the compressive force, concrete spalling, exposure, and torsion of longitudinal rebars at the boundary area were generated after the peaking load point. The lateral resistance subsequently decreased sharply till the termination point when the specimen failed by a loss of $15 \%$ 

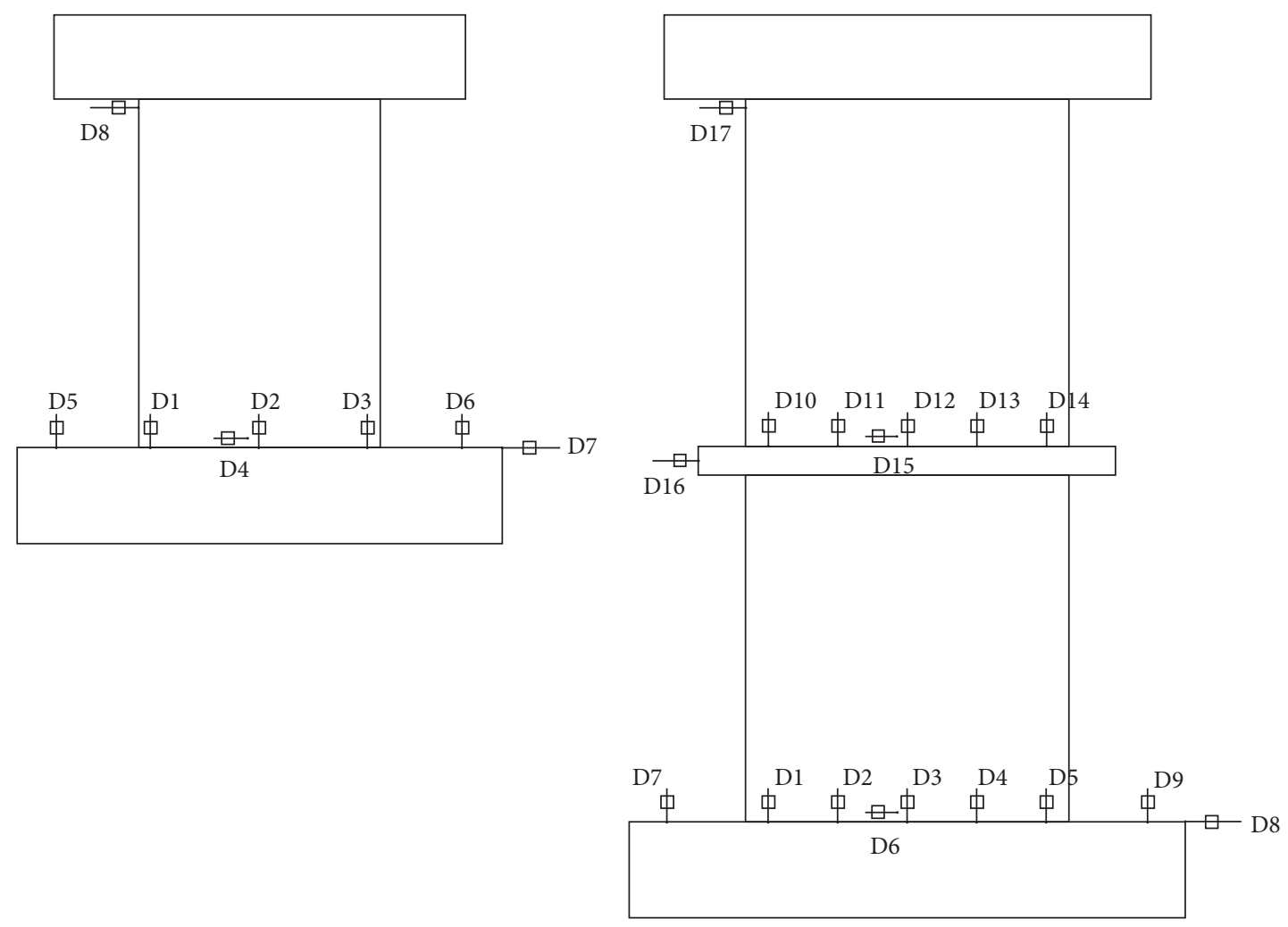

(a)

(b)

FIgURE 5: Measurement scheme. (a) Group 1. (b) Group 2.
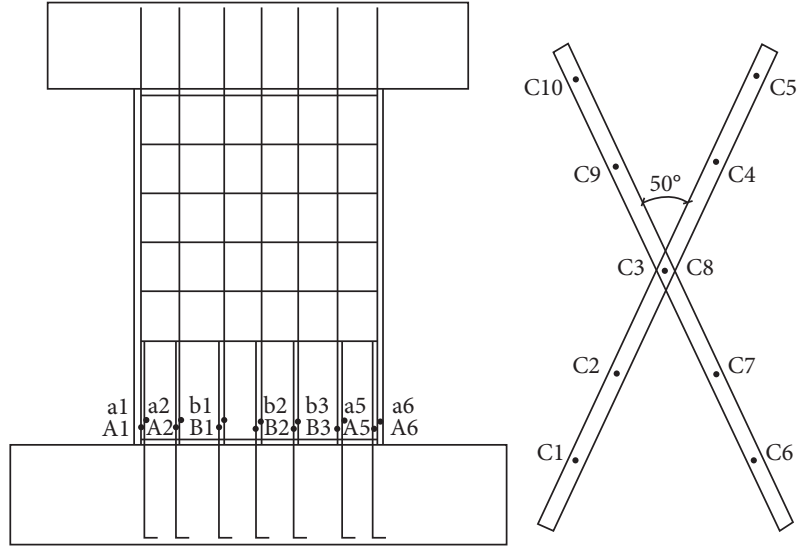

(a)
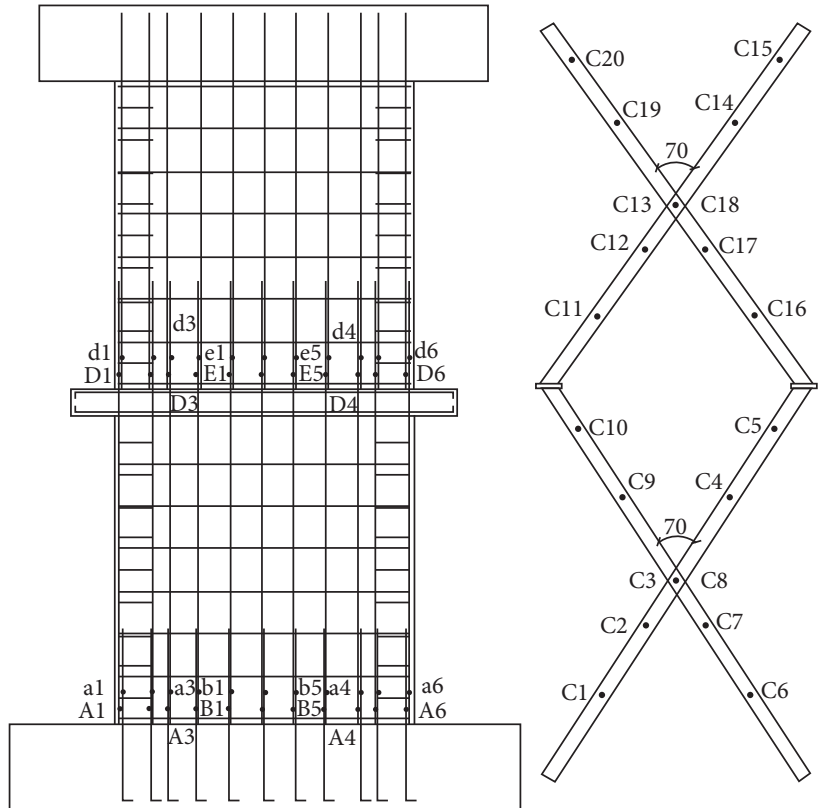

(b)

Figure 6: Arrangement of strain gauges. (a) Group 1. (b) Group 2.

of its peak resistance capacity. As presented in Figure 7(d), the specimen exhibited flexural dominated failure mode.

SRCSW2-1 and SRCSW2-2 experienced similar cracking development to that of SW2. At the top displacement of
$3.0 \mathrm{~mm}(\theta=0.09 \%)$, the first crack was measured at the surface between PC layer and CIP square notch of the $1^{\text {st }}$ story in both the two PC specimens, and the cracking load was $79.8 \mathrm{kN}$ for SRCSW2-1 and $81.1 \mathrm{kN}$ for SRCSW2-2 in 


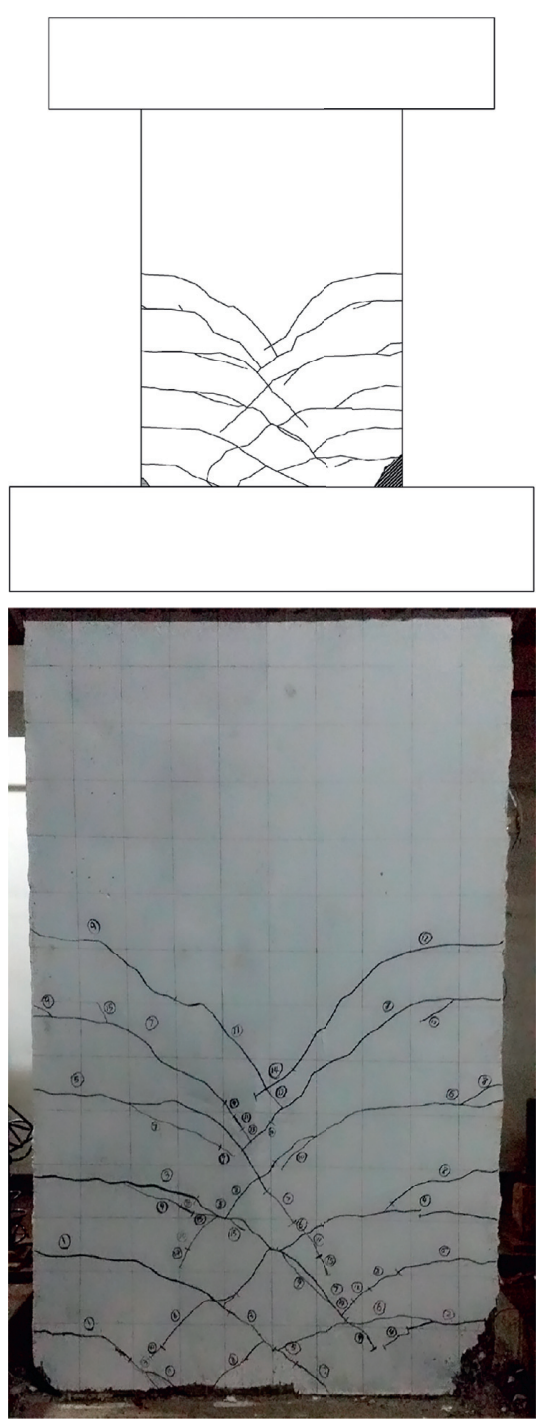

(a)
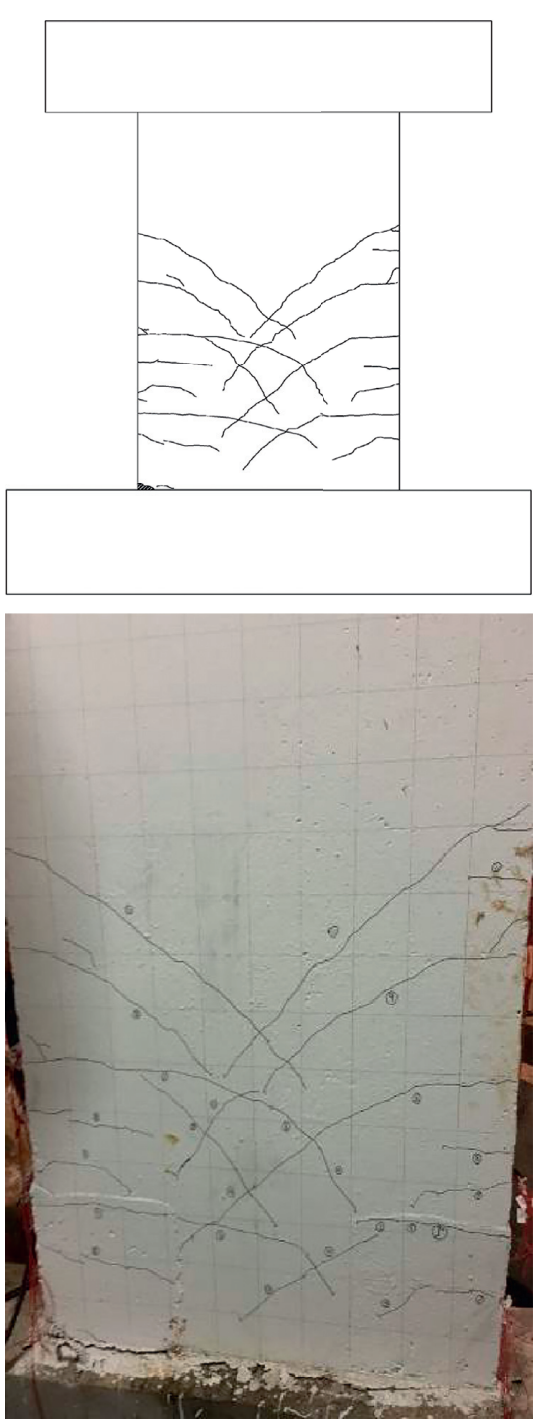

(b)
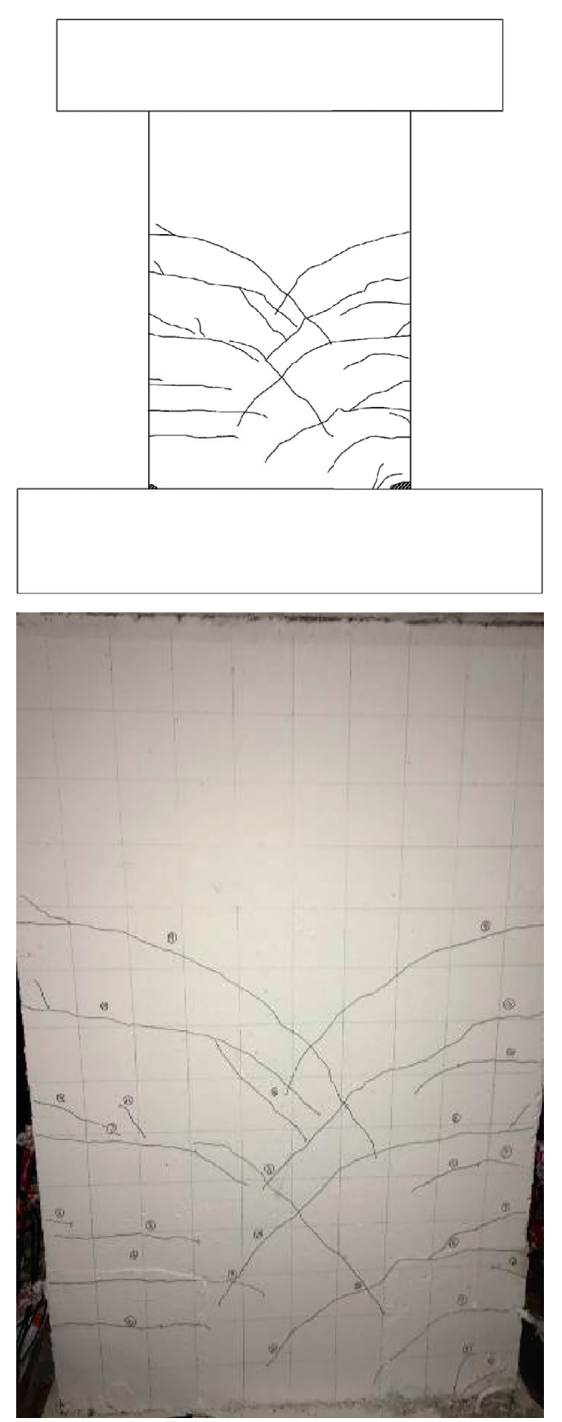

(c)

Figure 7: Continued. 


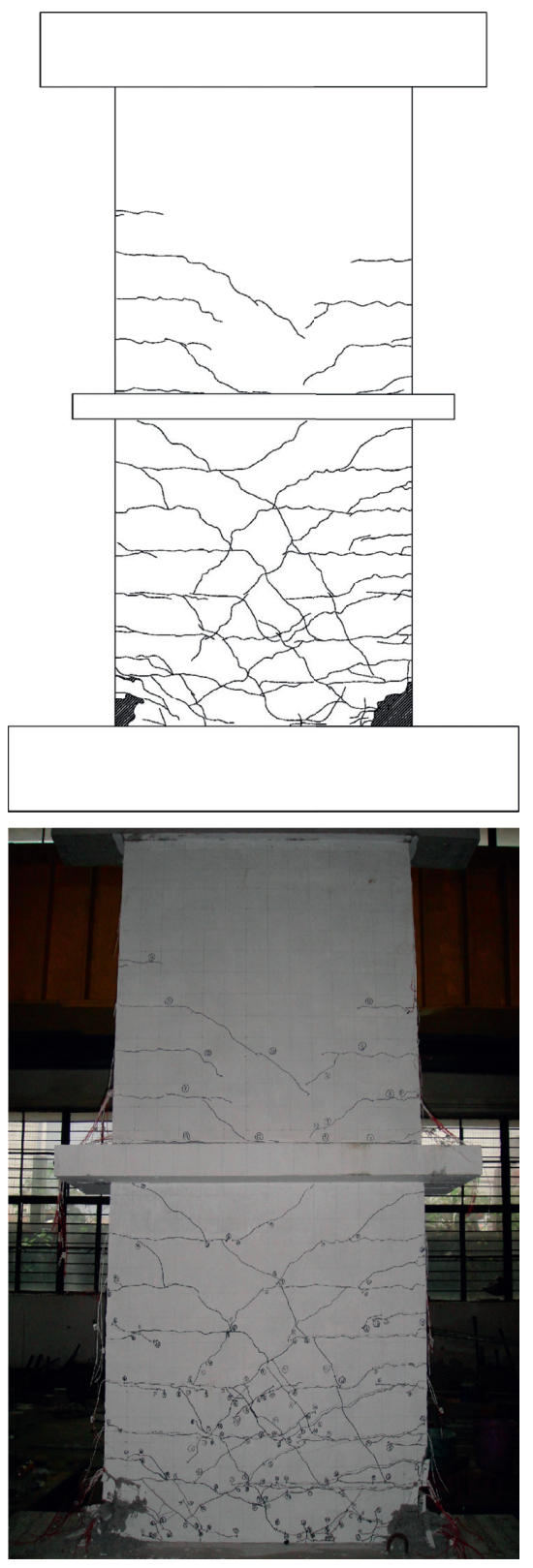

(d)
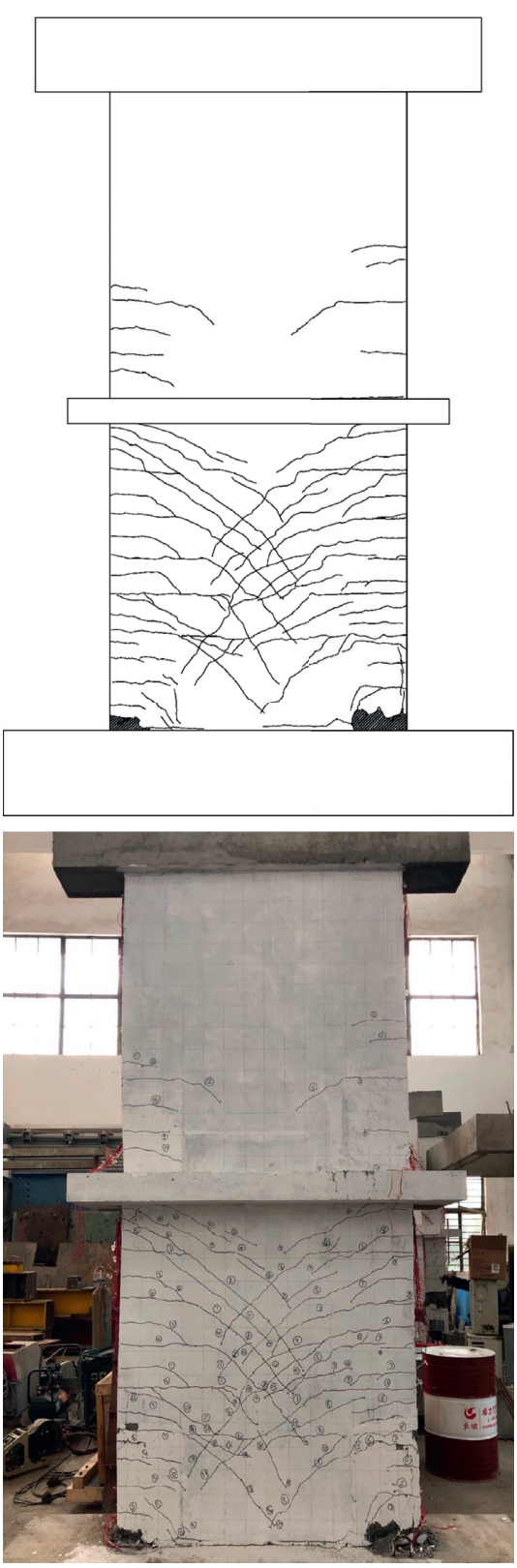

(e)
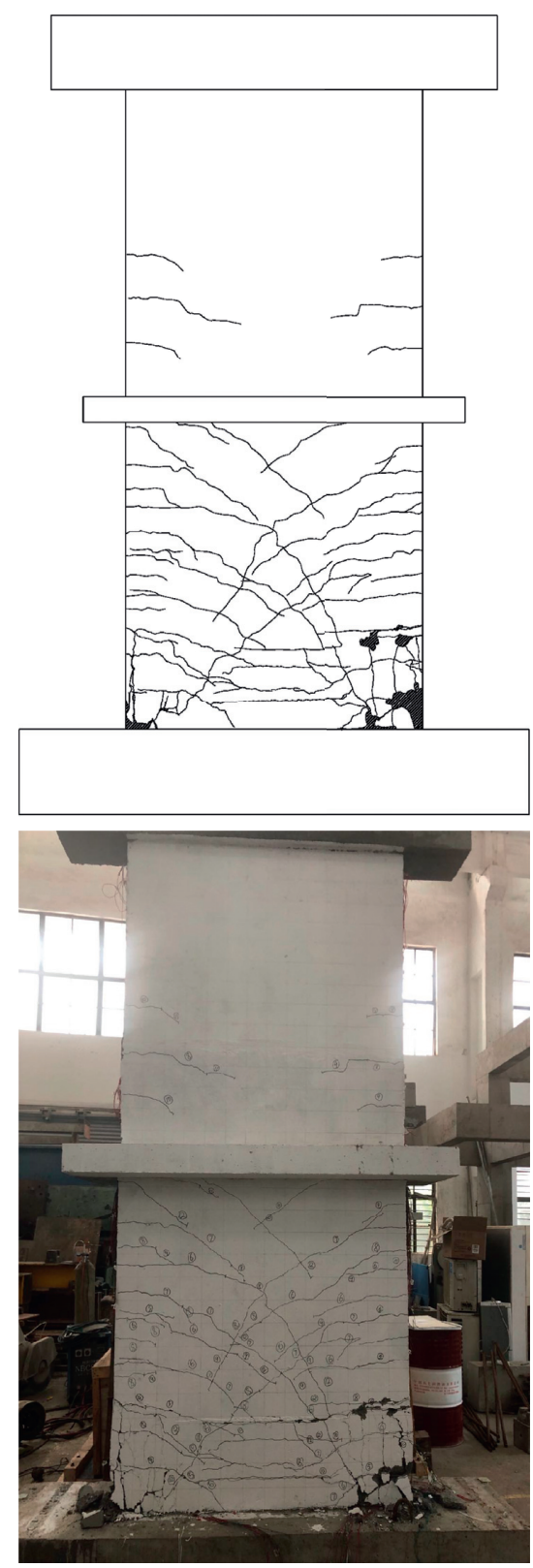

(f)

FIgURE 7: Cracking patterns of specimens. (a) SW1. (b) SRCSW1-1. (c) SRCSW1-2. (d) SW2. (e) SRCSW2-1. (f) SRCSW2-2.

positive direction. At the displacement level of $45.0 \mathrm{~mm}$ $(\theta=1.41 \%)$, SRCSW2-1 attained the peak bearing capacity of $306.1 \mathrm{kN}$, and SRCSW2-2 reached the maximum load of $310.9 \mathrm{kN}$ in average, which are $5.7 \%$ and $4.3 \%$ lower than that of SW2. Meanwhile, the cover concrete of the compressive end began to spall off and rocking crack occurred, indicating that bond strength of the boundary area decreased as the cyclic loading proceeded. Visible gap opening with a maximum width of $6.42 \mathrm{~mm}$ was documented at the tension side of SRCSW2-1 when loaded to $45.0 \mathrm{~mm}$, inferring that the lap splicing joint at the boundary region damaged (as depicted in Figure 8(a)). The PC specimens exhibit similar crack pattern which was of traditional flexural dominated type. When subjected to the cyclic load, the cracks of the tested specimens were initiated at the boundary region and propagated at $45^{\circ}$ inclination downward the center of the wall panel. It was found that the brittle concrete crushing converged at both toes of the wall bottom, which behaved as the plastic region (as depicted in Figure 8(b)).

Differences in the final failure pattern between the two groups of specimen are clearly illustrated in Figure 7. The cracks of the PC specimens in group 1 were of flexural-shear type. As a result of substantial shear behavior, concrete crushing at the wall toe by the bending is not obvious. Furthermore, shear sliding and bond slip were concentrated at the connection joint area, bringing down the lateral resistance. As for the PC specimens with SSR value of 2.28, numerous flexural cracks are recorded. It is notable that the cracks were mainly concentrated at the $1^{\text {st }}$ 


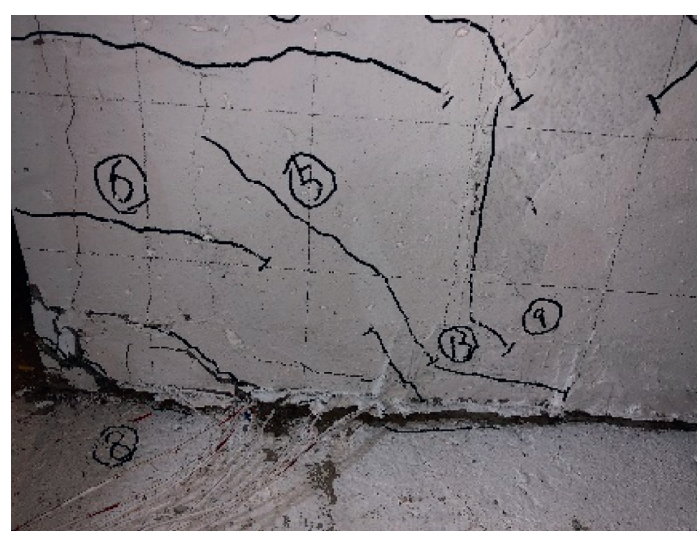

(a)

FIgURE 8: Typical damage of specimens.

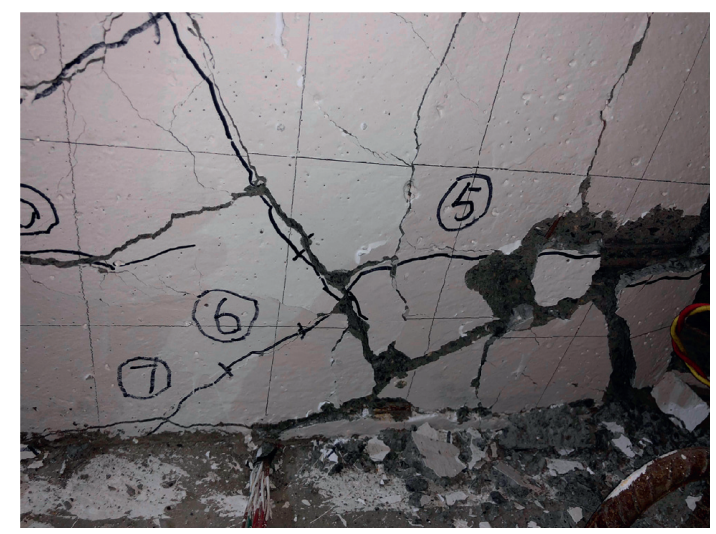

(b)

(a) Gap opening. (b) Concrete crushing.

wall panel, while few cracks were observed in the $2^{\text {nd }}$ story. This indicated that the CIP floor slab could inhibit the cracks from propagating upward. Coupled with the obvious gap opening of wall-to-foundation interface due to the tensile stress, concrete crushing at both ends of the wall toe due to the compressive stress is also documented, indicating that the lap splicing connectors at the hidden column in SRCSW2-1 and SRCSW2-2 are damaged severely by the cyclic load. Moreover, as a result of the larger SSR, the specimens in group 2 behave as compression members with larger eccentricity than that of the specimens in group 1 with the smaller SSR value of 1.63 , revealing more severe compressive damage at the wall toes. The observed failure mechanism implied that it should ensure sufficient shear resistance for the flexural-shear-interaction specimen and strengthen the load bearing capacity of boundary region for the flexural dominated specimen.

3.2. Load-Displacement Response. The lateral force-top displacement hysteretic curves of the tested specimens are shown in Figure 9. The curves were linear before the specimen cracked. With the increasing of top displacement, the curve became nonlinear and the enclosed area of the curve enlarged in response to the cracking development and concrete damage. The loops generated by the force-displacement curve had spindle shape before the peaking load point and then displayed pinching effect due to the stiffness degradation.

The plumpness of the hysteretic curve of the CIP specimens is slightly greater than that of the PC specimens, and the enclosed area of CIP specimen is larger for the reason that the ultimate imposed displacement of SW 1 and SW2 is larger compared with the PC specimens. For instance, the loading test of SW1 proceeded to $30.0 \mathrm{~mm}$, while the test of SRCSW1-1 ended at the displacement of $27.0 \mathrm{~mm}$. The residual displacement for each cycle at the yield stage is comparable for both the PC walls and CIP walls, revealing that the PC specimen experienced similar cyclic response to that of the full integrity wall, without distinct slide occurring.
Figure 10 presents the skeleton curves of all the tested specimens. The values of story drift and the lateral force of the key characteristic points in terms of crack point, yield point, peak point, and ultimate point as well as ductility are summarized in Table 3. The yield point is determined by the equivalent area method suggested by Park [33], and the ultimate point is defined as the time when the load dropped to $85 \%$ of the peak load. The story drift is derived from (1), where $\Delta_{i}$ stands for story displacement and $H_{i}$ denotes the story height. The ductility is determined from (2).

$$
\begin{gathered}
\theta=\frac{\Delta_{i}}{H_{i}}, \\
\mu=\frac{\theta_{u}}{\theta_{y}} .
\end{gathered}
$$

For each group, the curves are almost identical before the yield load point, indicating that the PC specimens have stiffness comparable to that of CIP specimens. However, the peak strength of the specimen in group 1 varied because of the differences in material property and deformation behavior. The peak strength of SRCSW1-2 is $11 \%$ lower than that of SW1, which is partly because the concrete strength is $12 \%$ lower than that in CIP specimen. The occurrence of visible gap opening at the wall-to-foundation area of SRCSW1-1 may account for the lower peak strength compared with SRCSW1-2. As for the specimens in group 2, the two PC specimens have comparable bearing capacity with the benchmark specimen SW2. However, the load bearing capacity decreased sharply after the peak load point. This is mainly because, under cyclic loading, substantial crushing of concrete results from compression and bond-slip failure of the lap splicing joint generated at the wall toe, inducing the sharp inclined curve after the peak load point.

As shown in Table 4 , the drift ratios $\left(\theta_{\mathrm{cr}}\right)$, when the initial cracking of specimen was documented, are in an intensive range of $0.09 \% \sim 0.14 \%$. The ductility ratio $\left(\mu_{\Delta}\right)$ of the $\mathrm{PC}$ specimens is lower than that of the CIP specimens in group 1 , and the specimens in group 2 exhibit the same ductility. The ultimate drift of the PC specimens is approximately $2 \%$, greatly satisfying the plastic drift limit of 1/120 specified in 


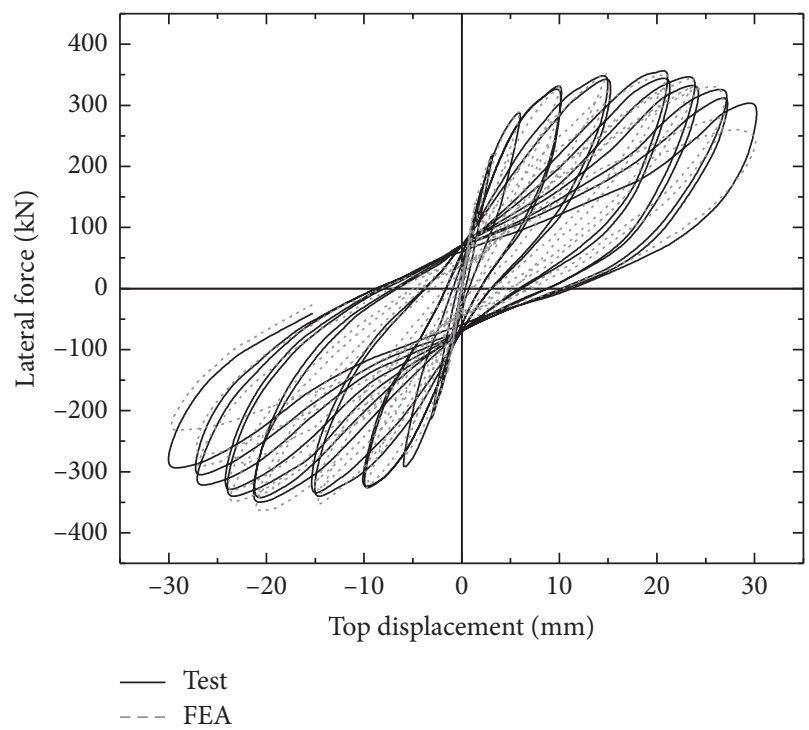

(a)

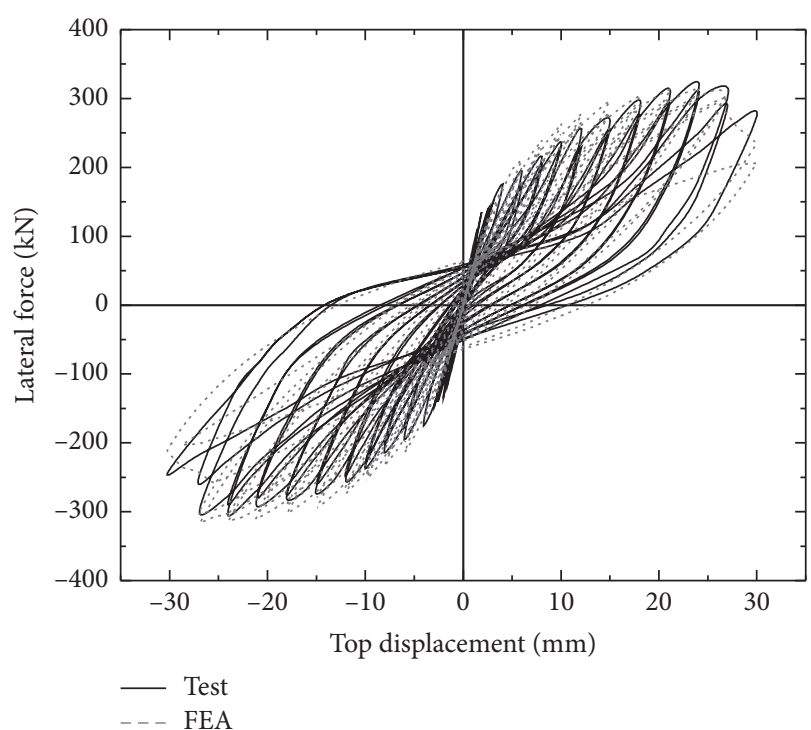

(c)

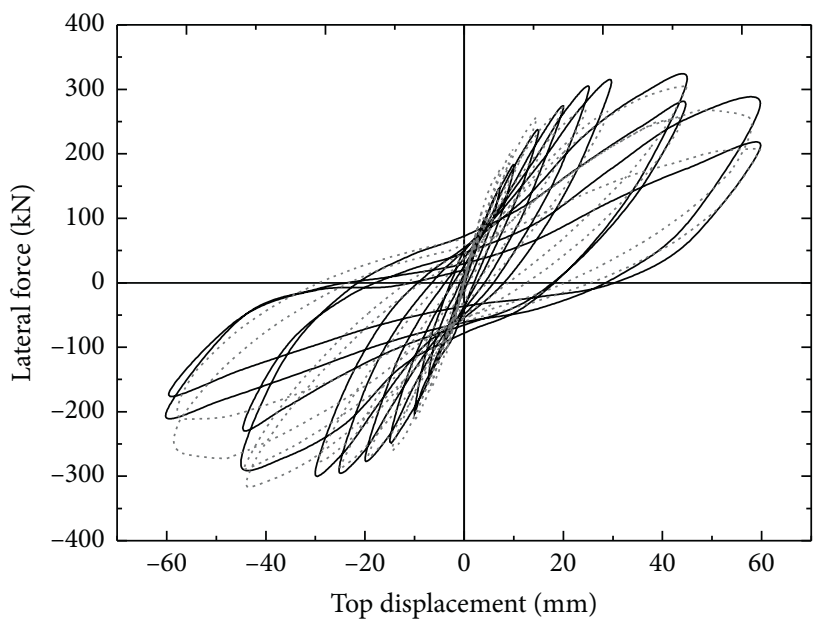

- Test

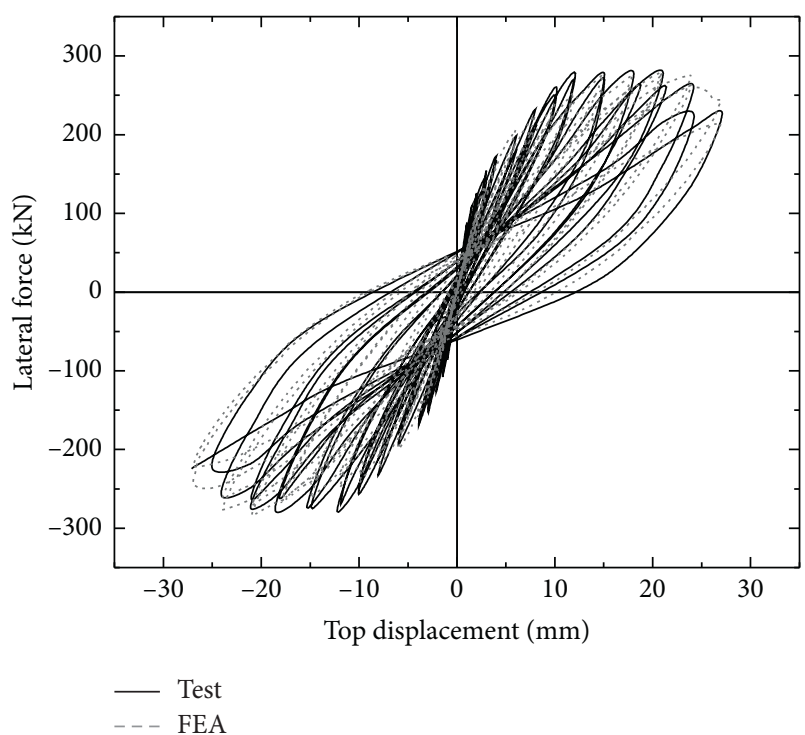

(b)

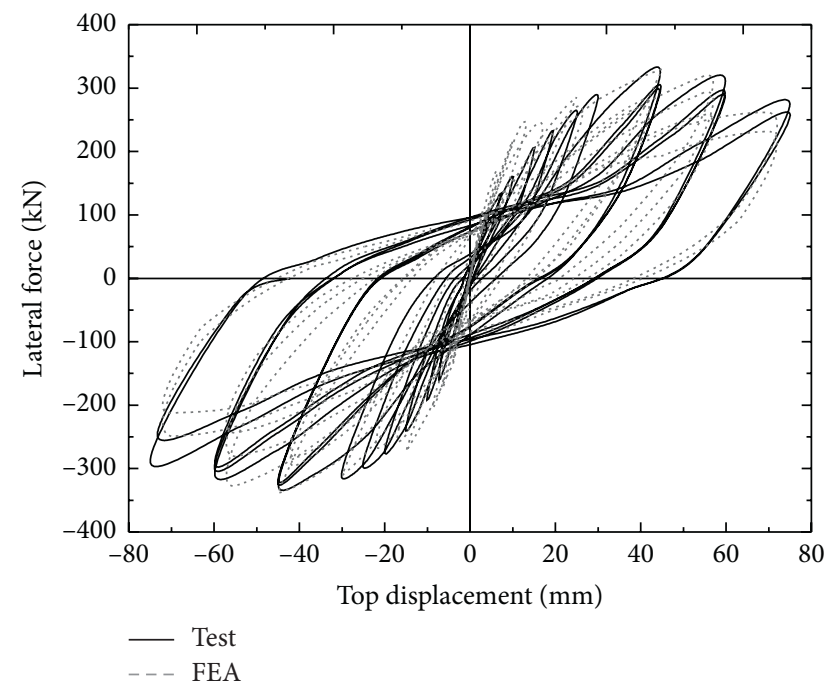

(d)

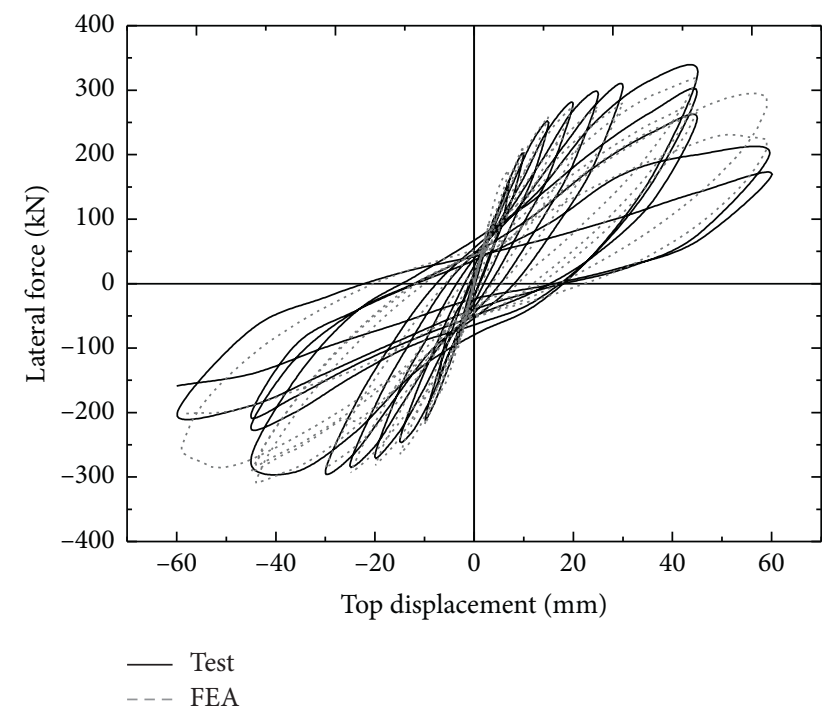

(f)

Figure 9: Hysteretic curves. (a) SW1. (b) SRCSW1-1. (c) SRCSW1-2. (d) SW2. (e) SRCSW2-1. (f) SRCSW2-2. 


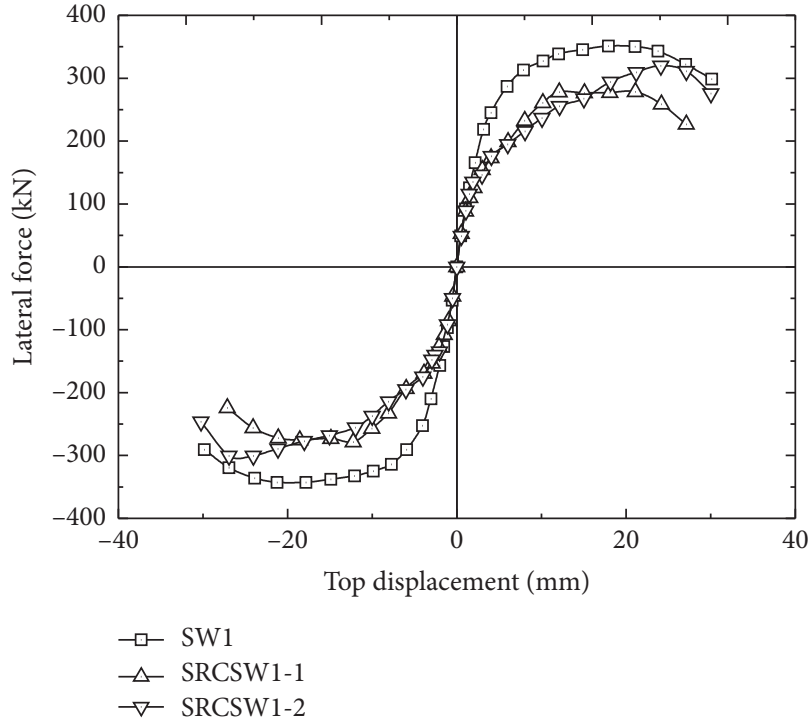

(a)

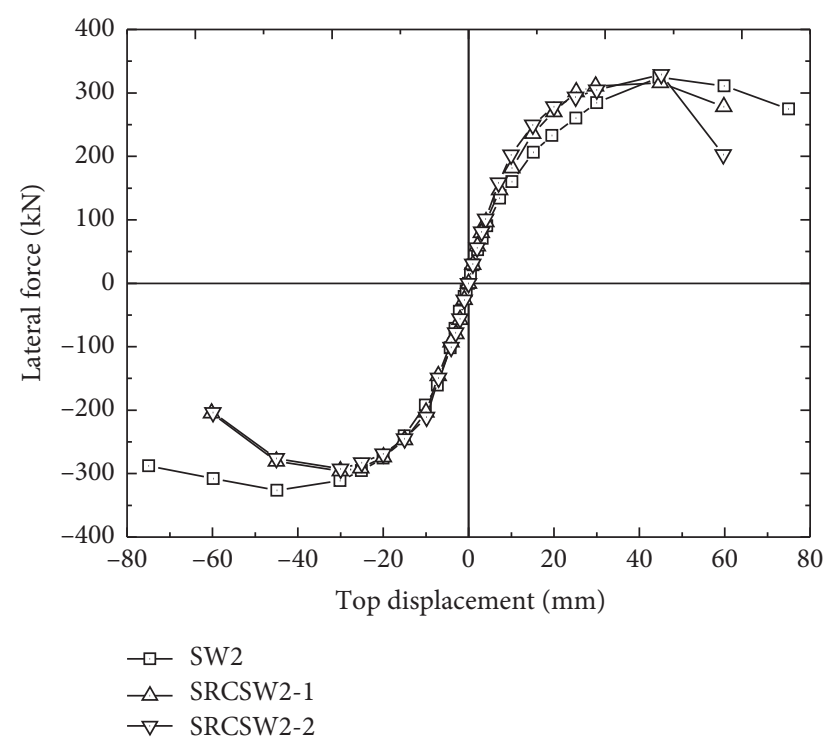

(b)

Figure 10: Skeleton curves. (a) Group 1. (b) Group 2.

TABLE 3: Characteristic values of the test results.

\begin{tabular}{lcccccccc}
\hline \multirow{2}{*}{ Specimen } & \multicolumn{2}{c}{ Crack point } & \multicolumn{2}{c}{ Yield point } & \multicolumn{2}{c}{ Peak point } & \multicolumn{2}{c}{ Failure point } \\
& $V_{\mathrm{cr}}(\mathrm{kN})$ & $\theta_{\mathrm{cr}}(\%)$ & $V_{y}(\mathrm{kN})$ & $\theta_{y}(\%)$ & $V_{m}(\mathrm{kN})$ & $\theta_{m}(\%)$ & $V_{u}(\mathrm{kN})$ & $\theta_{u}(\%)$ \\
\hline SW1 & 161.2 & 0.14 & 292.9 & 0.53 & 349.4 & 1.37 & 294.5 & 2.08 \\
SRCSW1-1 & 126.3 & 0.14 & 220.6 & 0.51 & 278.4 & 1.28 & 230.4 & 1.85 \\
SRCSW1-2 & 146.9 & 0.21 & 244.1 & 0.68 & 310.8 & 1.67 & 258.4 & 2.04 \\
SW2 & 96.15 & 0.14 & 277.2 & 0.83 & 324.6 & 1.54 & 281.5 & 2.47 \\
SRCSW2-1 & 79.8 & 0.09 & 270.9 & 0.67 & 306.1 & 1.16 & 241.4 & 3.0 \\
SRCSW2-2 & 79.5 & 0.09 & 263.9 & 0.65 & 310.9 & 1.16 & 203.6 & 1.98 \\
\hline
\end{tabular}

TABLE 4: Shear-slip displacement of wall-to-foundation area of the PC wall.

\begin{tabular}{|c|c|c|c|c|c|}
\hline Specimen & Direction & $\Delta_{s, y}(\mathrm{~mm})$ & $\Delta_{s, m}(\mathrm{~mm})$ & $\Delta_{m}(\mathrm{~mm})$ & $\Delta_{s, m} / \Delta_{m}(\%)$ \\
\hline \multirow{2}{*}{ SRCSW1-1 } & + & 0.54 & 1.49 & 21.09 & 7.06 \\
\hline & - & 0.51 & 0.82 & 18.56 & 4.40 \\
\hline \multirow{2}{*}{ SRCSW1-2 } & + & 0.34 & 1.33 & 24.10 & 5.51 \\
\hline & - & 0.38 & 1.12 & 24.03 & 4.67 \\
\hline \multirow{2}{*}{ SRCSW2-1 } & + & 0.52 & 0.86 & 44.98 & 1.87 \\
\hline & - & 0.45 & 1.09 & 45.02 & 2.42 \\
\hline \multirow{2}{*}{ SRCSW2-2 } & + & 0.45 & 0.90 & 45.12 & 1.99 \\
\hline & - & 0.53 & 1.10 & 45.03 & 2.44 \\
\hline
\end{tabular}

Chinese code for seismic design (GB 5011-2010) [34]. In both the flexural-shear-interaction group and the flexural dominated group, the load bearing capacity of PC specimens characterized by bolted steel connector is superior to that of the specimens constructed with spiral hoop connectors.

3.3. Stiffness Degradation. The relationship between stiffness and top displacement of the tested specimen is demonstrated in Figure 11, in which the stiffness is the maximum of strength in relation to the top displacement at each supposed load step. Both the CIP and PC specimens experienced similar stiffness degradation. The stiffness decreased sharply at the early stage of loading test. The curves tend to be steady with the development of cracks on the wall specimen. It can be found that, in the first group, the stiffness of the PC specimens is generally lower than that of the corresponding CIP specimens during the phase between the yield point and the ultimate point. This is mainly because of the shear slide generated at the construction joint that affected the lateral stiffness. However, with the increase of imposed displacement, substantial concrete cracks are fully developed and comparable concrete damage is generated in both CIP and PC specimens, leading to insignificant difference in stiffness 


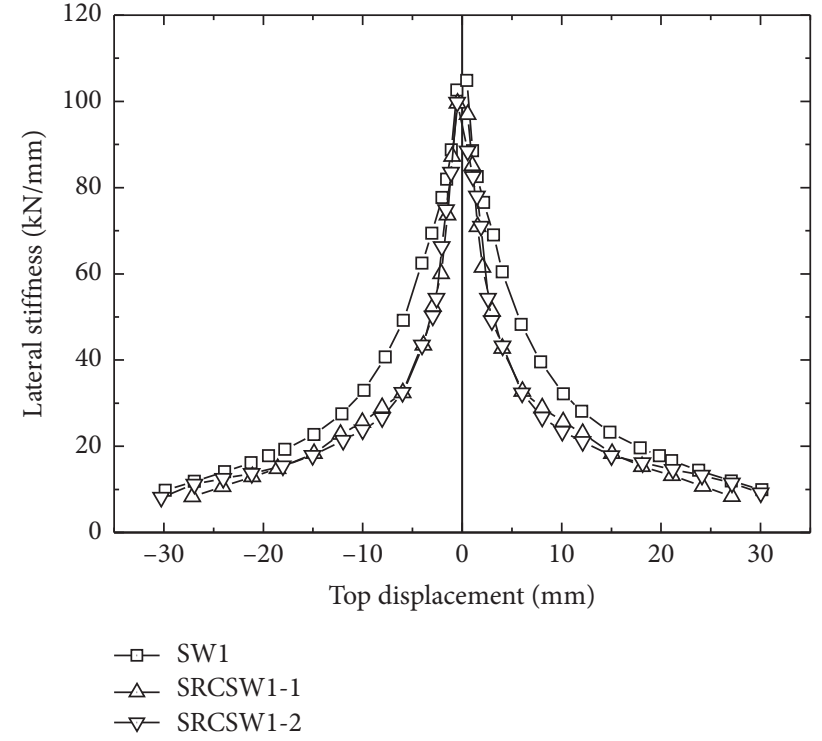

(a)

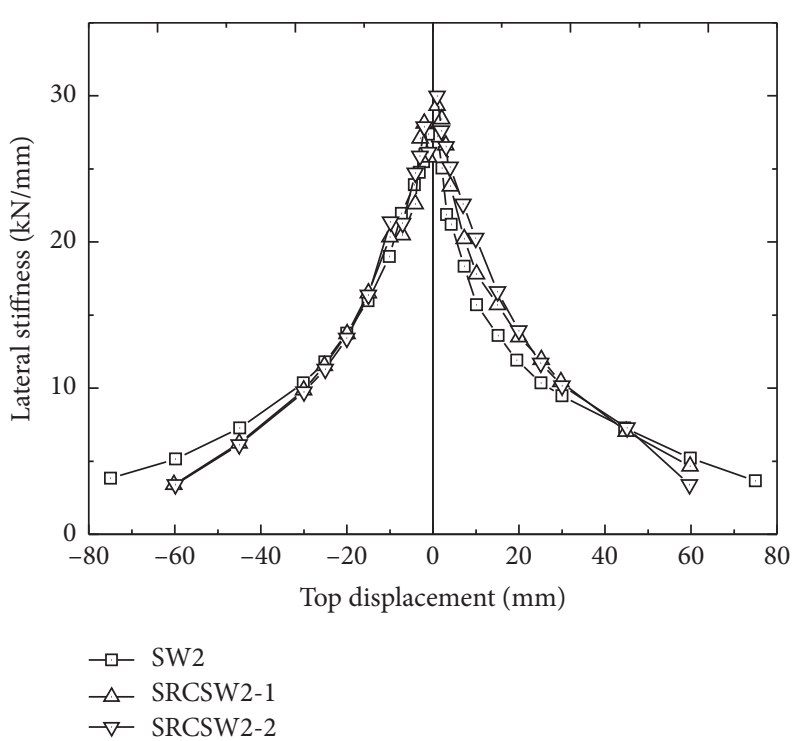

(b)

Figure 11: Secant stiffness degeneration curves of specimens. (a) Group 1. (b) Group 2.

at the ultimate state. As for the flexural controlled specimens in group 2, the stiffness degradation curves of the three specimens seem to be identical till the peak load point, during which time the bond strength is adequate to resist the applied force. However, due to the brittle damage occurring at the wall toe in the later loading stage, SRCSW2-1 and SRCSW2-2 exhibit a slightly sharper curve compared with SW2.

3.4. Strain Response. The strain responses of the key strain gauges mounted at the longitudinal rebars of the connection joint are shown in Figure 12, which represent the relationship between strain and lateral force. According to the tension test, the yield strains of $\Phi 10$ rebars located at the wall panel and $\Phi 12$ rebars located at the boundary column are evaluated as $2312 \times 10^{-6}$ and $2442.5 \times 10^{-6}$, respectively. As the strain of reinforcement changed dramatically after the reinforcement yielding, only strains under $4000 \times 10^{-6}$ are considered in this section.

In general, the skeleton curves of strain are characterized by asymmetry and a bit of irregularity for the reason that the normal direction of the strain gauges is not consistent with the lateral loading direction. However, the comparison of strain development between the upper measuring point of the wall and lower measuring point at the bottom of the wall segment can reflect the cohesive status and the force transferring action along the reinforcement to a certain extent. For instance, great inconsistency was demonstrated between the upper and lower measuring point of the lap splicing bar at the boundary column in SRCSW2-2, as shown in Figure 12(a). When SRCSW2-2 was loaded with $293.6 \mathrm{kN}$, the measured strain of A1 was $2417 \times 10^{-6}$, approaching the yield point for $\Phi 12$ rebar, while the strain of a1 is $1063 \times 10^{-6}$, significantly lower than that of A1. With the increase of top displacement, the growth of strain in lower reinforcement was far greater than that of the upper reinforcement; the great difference in strain curve indicated that the load transferring of lap splicing bars is undesirable. As for the specimen SRCSW2-1 with spiral hoop connector, the growth of strain value of the upper and lower measure points tends to be generally consistent before the crack point. However, the two skeleton curves in Figure 12(b) became disjunctive with the increase of lateral force. This is mainly because the cohesive strength of the connecting rebar and spiral hoop decreased, and the bond slip was subsequently generated along the reinforcement. As shown in Figure 12(c), the strain development of the upper and that of the lower reinforcements connected by the bolted steel connector are mainly synchronous, indicating that the force transferring through the friction or squeezing action of bolted steel connectors ensured satisfactory load transferring.

3.5. Relative Displacement within the Connection Joint. There were a series of dial gauges arranged at the connection joint area to measure the relative displacement in vertical and horizontal direction. According to the collected data, slip deformation is mainly concentrated at the wall-tofoundation interface, and the relative displacement along the wall of the PC specimens is depicted in Figure 13.

As for the PC specimens with single wall panel, the gap opening within the connection joint was relatively narrow at the top displacement of $6.0 \mathrm{~mm}$. When the specimens reached their peak load point, the distribution of joint opening along the wall length is almost linear, where the deformation at the tension side was greatly larger than that at the opposite side. The substantial deformation occurring at the wall-to-foundation area indicated the bonding failure of connection joint. Furthermore, the maximum deformation of SRCSW1-1 is 


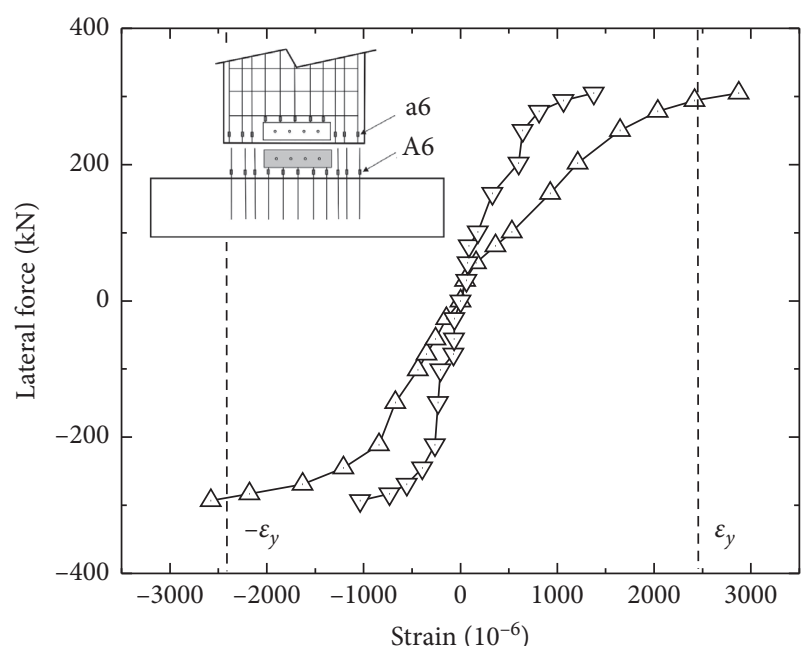

$\begin{array}{ll}\triangle & \text { A6 } \\ -\nabla-\text { a6 }\end{array}$

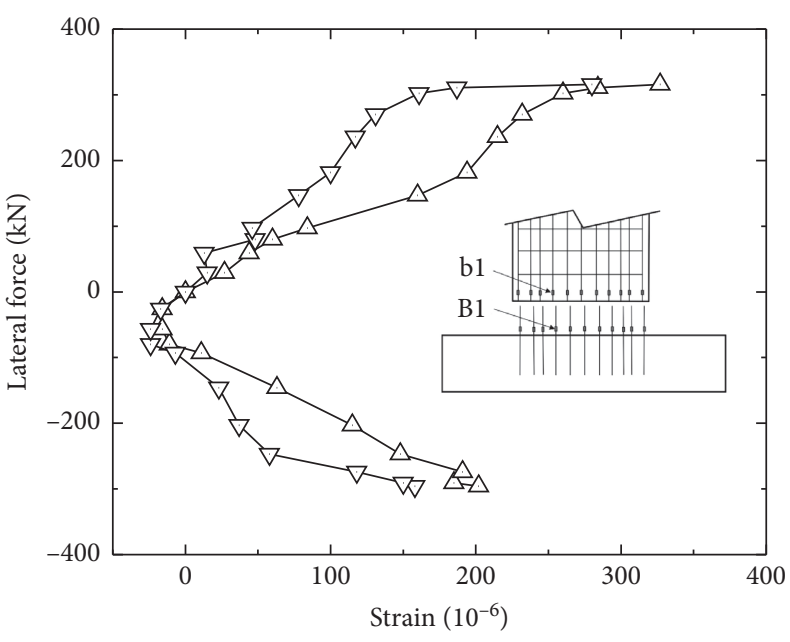

$\triangle \mathrm{B} 1$

$\nabla$ b1

(a)

(b)

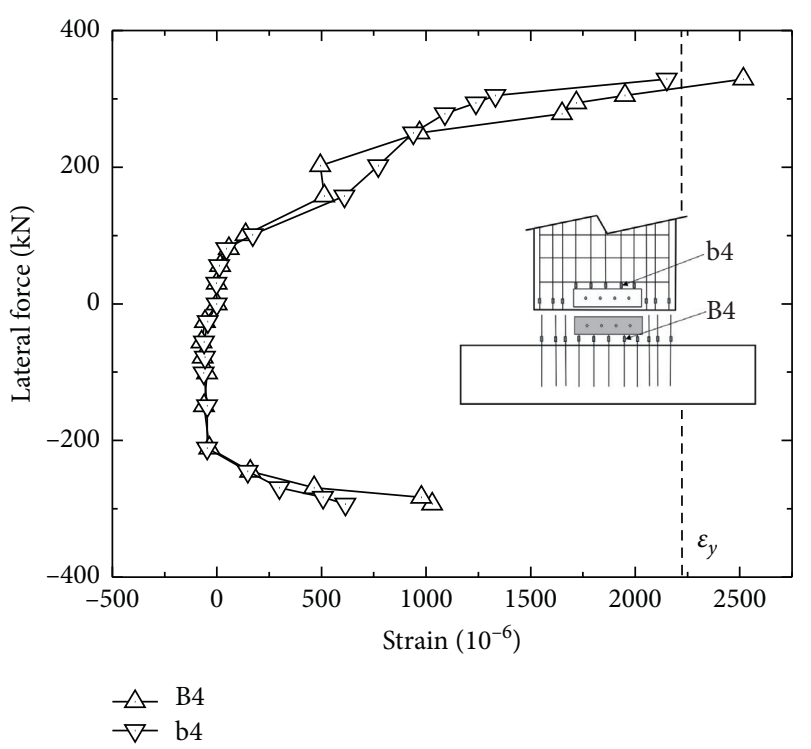

(c)

FIgure 12: Skeleton curves of strain. (a) a6 and A6 of SRCSW2-2. (b) b1 and B1 of SRCSW2-1. (c) b4 and B4 of SRCSW2-2.

larger than that of SRCSW1-2 at the corresponding peak load point.

Constructed by two PC panels, the PC specimens in group 2 are flexural controlled. As shown in Figure 13, the deformation of the wall-to-foundation section of the two specimens is linear approaching the yield point, and the joint opening is negligible. The specimen maintained approximately elastic status with little concrete damage accumulated. However, slip distribution curves became irregular as bond slip is generated dissimilarly at the construction joint. When applied to the peak loading point, coupled with vertical compressive cracks, abrupt concrete damage occurred at the boundary area due to the repeated compressive and tensile action, resulting in severe bonding slip failure.
Furthermore, vertical deformation at the spiral hoop and bolted steel connection joint area at the wall panel was documented. The deformation generated at the spiral hoop connectors is greater than that of bolted steel connectors utilized in SRCSW2-2. The maximum deformation of SRCSW2-1 and SRCSW2-2 was $6.42 \mathrm{~mm}$ and $5.02 \mathrm{~mm}$ when loaded to the top displacement level of $45 \mathrm{~mm}$, indicating that SRCSW2-2 possesses superior performance in bonding behavior.

In combination with the experimental phenomenon, the adopted spiral hoops could provide sufficient bond strength before the yield point of the tested specimen. The connecting bars were well bonded with the confinement of spiral hoops. However, with the processing of cyclic load, bond slip in line 

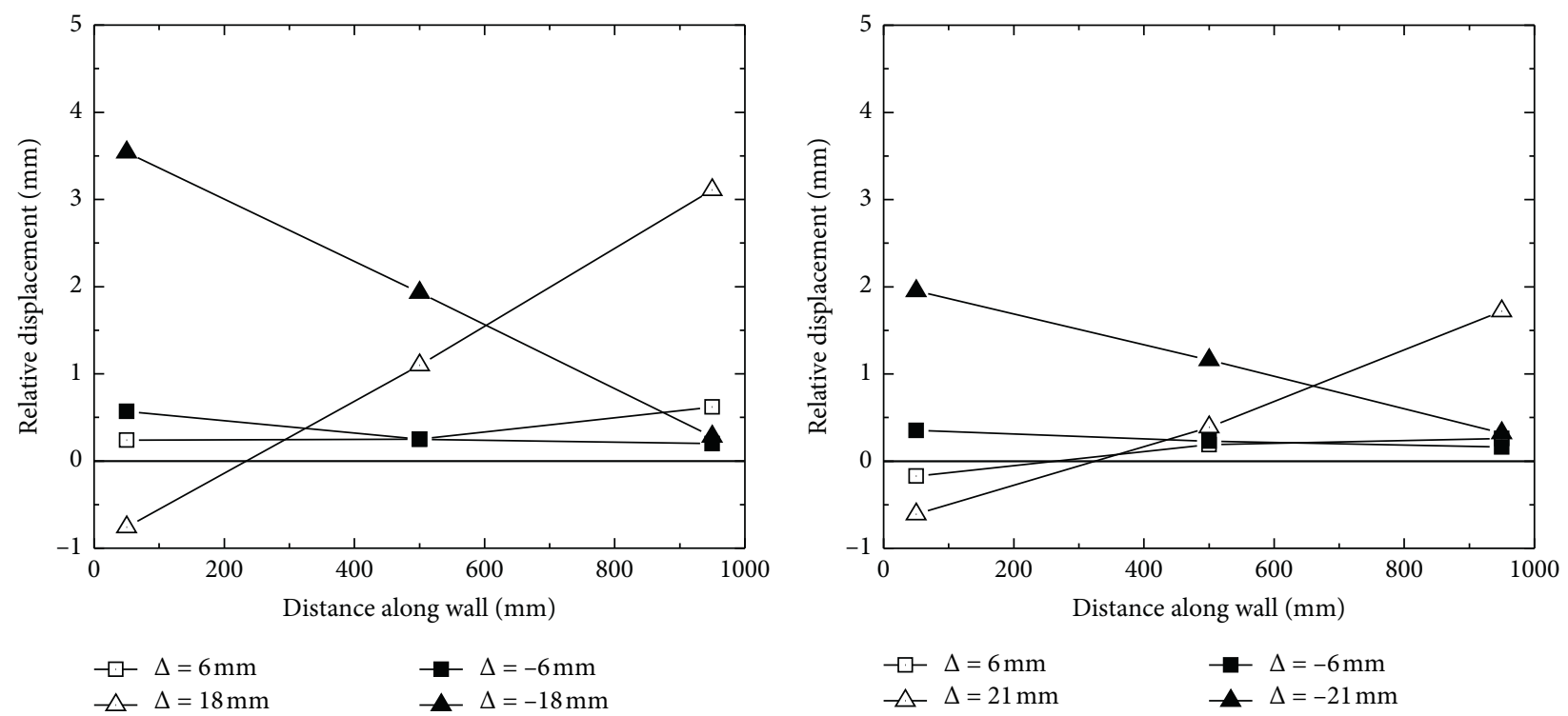

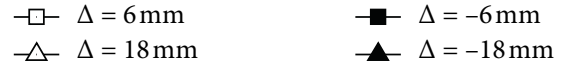

(a)

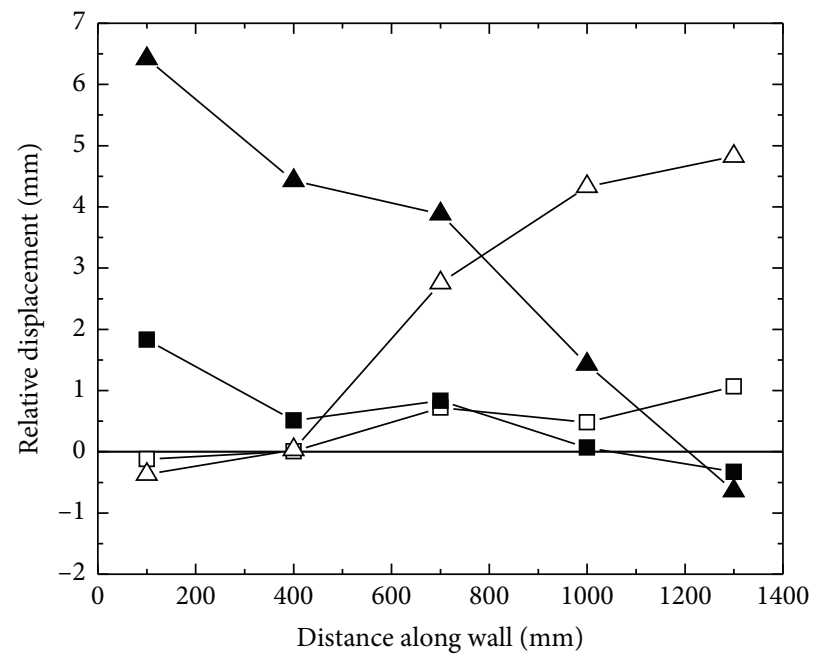

$\begin{array}{ll}\dashv \Delta=20 \mathrm{~mm} & \rightarrow \Delta=-20 \mathrm{~mm} \\ \neg \triangle \Delta=45 \mathrm{~mm} & \rightarrow \Delta=-45 \mathrm{~mm}\end{array}$

(c)

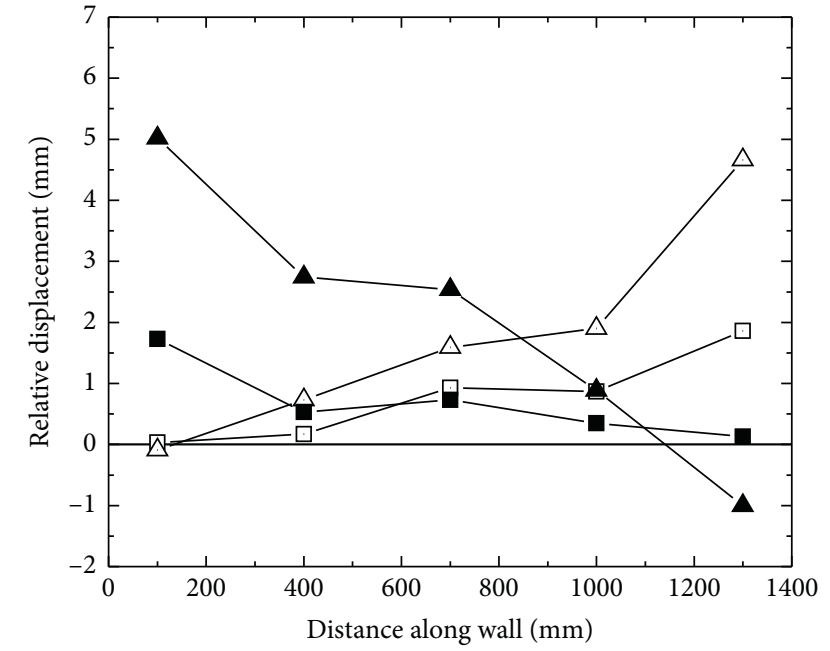

$\begin{array}{ll}\multimap \Delta=20 \mathrm{~mm} & -\Delta=-20 \mathrm{~mm} \\ \neg-\Delta=45 \mathrm{~mm} & -\Delta=-45 \mathrm{~mm}\end{array}$

(d)

FIGURE 13: Vertical relative displacement of wall-to-foundation area along the PC wall length. (a) SRCSW1-1. (b) SRCSW1-2. (c) SRCSW21. (d) SRCSW2-2.

with the concrete damage developed, resulting in a decrease of confinement provided by spiral hoops. Subsequently, slip deformation was generated along the connector. As for the bolted connection, the force between the upper and lower reinforcement was transformed by bond strength of the welding, the friction of high-strength bolts, and the shear resistance of the steel plate in combination with highstrength bolts successively. The force act along the longitudinal rebars welding on the plate is transferred by the friction of bolts in the bolted steel connector initially. When the applied load surpassed the load bearing capacity of the friction, slip deformation was generated in the range of the gap between the bolt and the bolt hole. The way transferring the load act along longitudinal rebars was replaced by the squeezing action of steel plate and bolt. Overall, the load transferring between the upper and lower reinforcement is clear and definite through the bolted steel connection joint, by which the slip deformation in PC specimen is negligible even when applied by extreme top displacement. Moreover, the bolted steel connection is found to be effective in restraining the rocking behavior.

In addition to the rocking phenomenon resulting in the vertical deformation along the wall length, shear slide is monitored by the dial gauge placed horizontally at the wallto-foundation area (referring to D4 in group 1, D6 in group 2). The skeleton curves of shear slip in relation to the lateral force are presented in Figure 14. The slide deformation of the tested specimens was almost zero before the specimens 


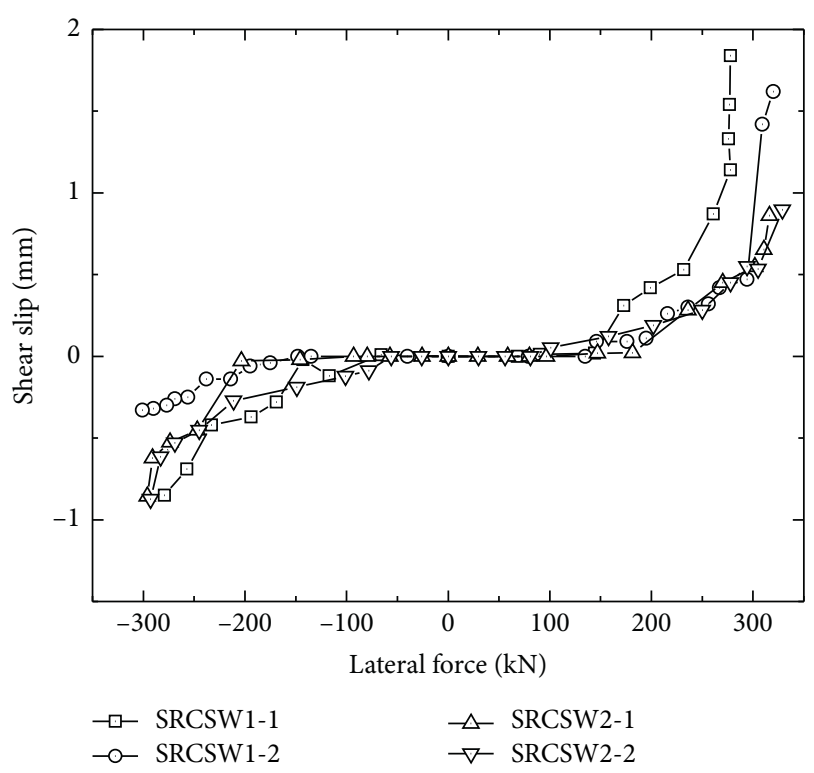

FIGURE 14: Shear-slip versus lateral force curves.

entered a yield stage, owing to the satisfactory shear resistance provided by $X$-shaped steel bracing and connection joint. However, due to the deterioration of connection joint, the horizontal relative displacement between the wall panel and the foundation beam enlarged as the cyclic loading proceeded. Table 3 lists the shear-slip deformation recorded at the yield point $\left(\Delta_{s, y}\right)$ and the peak point $\left(\Delta_{s, m}\right)$. When the specimens reached their peaking resistance, the ratio of the slip deformation to lateral displacement $\left(\Delta_{m}\right)$ was within the range from $4.4 \%$ to $7.06 \%$ for group 1 and from $1.87 \%$ to $2.44 \%$ for group 2. Because of a greater impact of shear behavior, the slip-to-displacement ratio in the single wall panel group is substantially greater than that in the two-story PC specimens. On the whole, with the contribution of $X$ shaped steel bracing and the proposed connection joint, the slip-to-displacement ratios at the ultimate status are greatly lower than that reported in the previous investigations (the maximum slip to top displacement by the quasistatic test of five PC wall specimens with different connecting joints by Chong et al. [1] and one I-shaped SRCSW specimen by Soudki et al. [17] were within the range from $12 \%$ to $35 \%$ ).

\section{Numerical Analysis}

As reported in previous numerical study, many analytical models were employed to simulate the seismic behavior of precast shear wall: (1) A 3D solid model generated by ABAQUS software was established to simulate the precast shear wall with grouting sleeve connections [35]. (2) A fiberelement model was established by Smith to evaluate the seismic performance of UPT wall [5]. (3) A shell element model using OpenSees [36] was adopted to reproduce the seismic behavior of precast Sandwich shear wall [37]. In the aforementioned research, the constitutive models of the force-slip relationship are defined by establishing spring element or zero-length element, with the aim of simulating the nonlinear behavior of construction joint. Regarding the outstanding computational efficiency and accuracy as well as the large quantity of specified material and elements, the finite element model comprised of shell elements and zerolength elements was developed to reproduce the cyclic loading response of the tested specimens in OpenSees platform.

4.1. The Modeling of Wall Panel. On the basis of the composite material mechanism theory, the multilayer shell element is recognized as a good measure to simulate the hysteretic behavior of shear wall. It has been validated that the THUShell element developed by Lu et al. [38] is capable of capturing both the in-plane and the out-of-plane behavior accurately. As schematically depicted in Figure 15, the wall web and the boundary column are modeled by shell elements. Except for the interstory floor slab, the two-story specimens in group 2 are modeled similarly to the specimens in group 1. For the wall web section, the loading beam as well as the interstory floor slab, the cover concrete, transverse and longitudinal rebars, and core concrete are smeared into a number of reinforcement and concrete layers. The boundary region was smeared into unconfined and confined concrete layer and the stirrup reinforcement layer, in which the longitudinal reinforcements are modeled by truss element. To strike a balance between calculation efficiency and accuracy, the mesh size of the shell elements is in the range from $150 \mathrm{~mm}$ to $200 \mathrm{~mm}$. The $X$-shaped steel bracing is modeled by beam-column element which could represent shear stiffness of the steel plate. All the truss elements and beam-column elements are coupled with the surrounding shell elements at the common nodes. Axial load, equal to the actual applied force, is uniformly distributed to each top node of the loading beam.

4.2. The Modeling of Material. The concrete materials are separated into unconfined and confined concrete according to their differences in confinement effect, and the constitutive models of the two types of concrete are depicted in Figure 16(a). The cover concrete of the wall section is simulated by unconfined concrete. The core concrete in wall web section, floor slab, and boundary column is simulated by confined concrete. The peak compressive strength of cover concrete was derived from the material test for concrete, and the residual strength of concrete at the crushing point was supposed to be zero. The peak compressive strength of confined concrete was computed by using the Mander model which could capture the confinement effect provided by stirrup, and the residual compressive strength is taken to be 0.2 times its peak strength. The constitutive mechanical model for the deformed rebars and steel plates is depicted in Figure $16(\mathrm{~b})$. The values of yield strength $\left(f_{y}\right)$ and elastic modulus $\left(E_{o}\right)$ are derived from the material test. The key parameters $\left(R_{o}, \mathrm{c} R_{1}, c R_{2}\right)$ to construct the elastic-plastic model are in accordance with previous work [39].

4.3. The Modeling of Joint Interface. The result obtained from the quasistatic test indicated that the connection joint of 


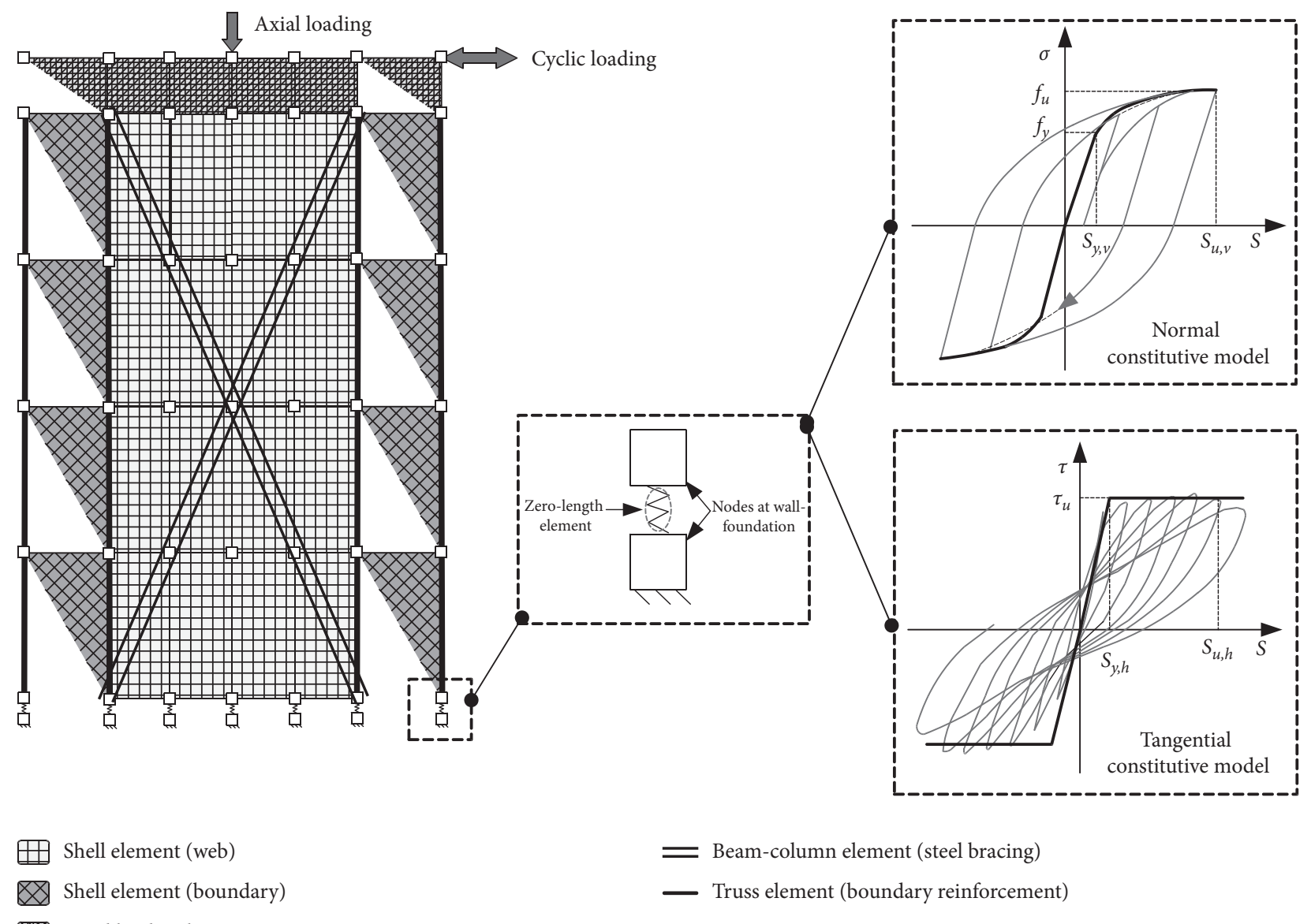

Figure 15: Schematic diagram of the FEA model.
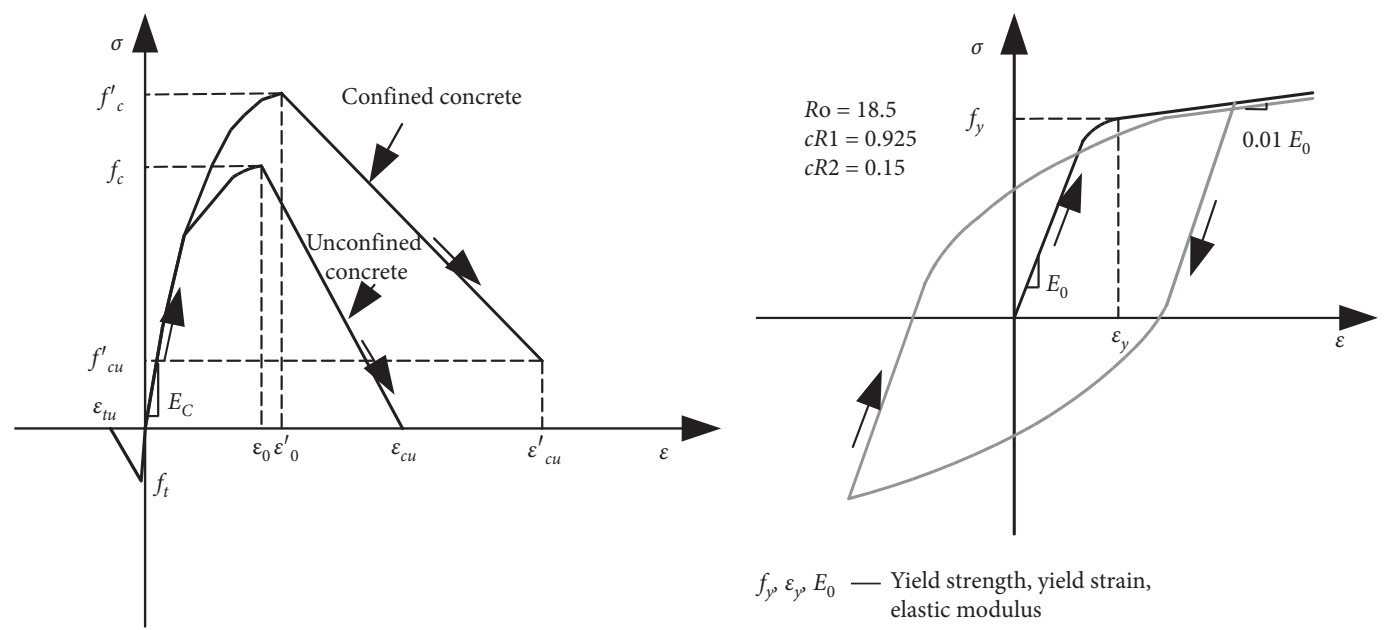

$$
\begin{aligned}
& f_{p} \varepsilon_{t u} \quad-\text { Tension strength } \\
& f_{\mathcal{C}}, \varepsilon_{0}, \varepsilon_{c u} \quad \text { Peak compressive strength, } \\
& \text { compressive strain at peak strength point, } \\
& \text { spalling strain (unconfined concrete) }
\end{aligned}
$$

(a)

Figure 16: Stress-strain curve for materials. (a) Concrete. (b) Steel. 
wall-to-foundation area experienced substantial slip deformation under cyclic loading due to the strength deterioration. The friction of old-new concrete and the dowel action of connecting reinforcements, as well as the bond strength between reinforcement and concrete, are the basic components for the complex mechanical behavior within the construction joint, which mainly account for the strength capacity for the connection joint. Bond slip or shear slip developed when the applied force surpassed the strength capacity, leading to slip within the connector.

In the simplified FE model, shear-slide and bond-slip model are defined by zero-length element in horizontal and vertical direction, respectively. Each zero-length element was placed at the corresponding position as the connecting bars for the tested specimen, connecting the nodes belonging to shell element of the upper PC panel and the node of the fixed foundation. By referring to the conclusion by large quantity of pull-out and cyclic load test conducted by Zhao et al. $[40,41]$ and Psycharis and Mouzakis [42], the normal bond-slip and tangential shear-slip constitutive model were defined.

$$
\begin{aligned}
S_{y, v} & =2.54\left[\frac{d \cdot f_{y}}{8437 \cdot \sqrt{f_{c}}}(2 \alpha+1)\right]^{1 / \alpha}+0.34, \\
\alpha & =0.4, \\
\frac{S_{u, v}}{S_{y, v}} & =30 .
\end{aligned}
$$

The normal bond-slip constitutive model is illustrated in Figure 15. The slip-force relationship can be described from (3) to (5), where $d$ represents the diameter of the connecting rebar. $f_{y}$ and $f_{u}$ denote the yield and the ultimate strength of the steel bar, respectively. $S_{y, v}$ and $S_{u, v}$ are the loaded-end slips when bar stresses are $f_{y}$ and $f_{u}$, respectively.

$$
\begin{aligned}
V_{R} & =1.3 d^{2} \cdot \sqrt{f_{c} \cdot f_{y}}, \\
\tau_{u} & =\frac{V_{R}}{S_{h}}, \\
S_{y, h} & =l_{a} \cdot \varepsilon_{y}, \\
\frac{S_{u, h}}{S_{y, h}} & =6 .
\end{aligned}
$$

The tangential shear-slip constitutive model is represented as (6)-(9), where $V_{R}$ denotes the shear resistance of a single zero-length element which comprised two connecting bars in a row. $S_{h}$ is the cover area of a zerolength element, which is equal to the spacing of longitudinal rebar multiplied by the thickness of wall specimen. $l_{a}$ and $\varepsilon_{y}$ denote the overlapping distance and yield strain of the connecting rebar.
4.4. Validation. According to the test phenomenon, all PC specimens showed slide deformation under reserved cyclic load; therefore, the horizontal shear-slide behavior is considered in all the PC specimens. The occurrence of vertical slip as a result of the bonding failure was detected in lap splicing connectors at boundary columns and spiral hoop connectors; hence, normal bond-slip constitutive relationship was defined in the boundary region for all the PC specimens and the web section in SRCSW1-1 and SRCSW21. The stress on the longitudinal bar connected by the bolted steel connectors is mainly transferred by the frictional behavior of the bolts and the squeezing behavior of the bolts and steel plate successively. The slip in this type of connector is limited to the gap between the bolt and the bolt holes, which is too small. Therefore, the bond-slip behavior in steel connection joint is neglected for simplicity. As a result of the continuity of longitudinal reinforcement and cast-in-situ casting, the CIP specimen showed excellent integrity, and the wall panel was simulated to be rigidly connected with the foundation.

The force-displacement responses obtained from the established FE models are represented in Figure 9. For simplicity, the complex mechanical behavior including the slip deformation and shear friction between the highstrength bolt and steel plate within the connection joint in SRCSW1-2 and SRCSW2-2 is ignored in the numerical simulation, which may account for the inconsistency between the numerical and experimental results. In addition, some asymmetry was found in the experimental curves as a result of the errors developed by loading system or data collection system, but the numerical simulation could avoid such accidental errors as it is performed ideally. The FEA results in the positive and negative directions are almost symmetrical. On the whole, the simulated curves exhibit satisfactory consistency with the test results in terms of strength, stiffness degradation, and pinching effect, even though the predicted strength at the elastic stage is slightly greater than that of the measured data due to the ideal constraint condition in numerical simulation. The comparison between the predicted and measured hysteretic curves indicated that the proposed FE models are capable of reproducing the cyclic behavior of the tested specimens.

\section{Conclusion}

This paper presented an experimental investigation into innovative SRCSW with spiral hoops and bolted steel connections. Constructed by single PC element or assembled by two individual PC panels, the specimens are divided into two groups to evaluate the seismic performances of the proposed SRCSWs by conducting quasistatic test. Major conclusions are drawn as follows:

(1) The proposed SRCSW specimens exhibited adequate seismic performance as that of the CIP specimens, except for the incomparable peak strength and 
ductility of flexural-shear-interaction PC specimens in group 1 due to the lower concrete strength. With the contribution of $X$-shaped steel bracing and sufficient bond strength of both spiral hoop and bolted steel connection joint, the slip-to-displacement ratio of the proposed SRCSW is greatly lower than that of traditional precast shear wall, and the rocking behavior is also restrained by the bolted steel connector. The proposed SRCSW showed acceptable integrity.

(2) The ultimate drift of all the PC specimens is about $1 /$ 50 , which greatly satisfies the plastic drift limit of $1 /$ 120 specified by GB 5011-2010. This indicates that the SRCSWs exhibit satisfactory deformation capacity.

(3) Both the spiral hoop connection and bolted steel connection are viable options for SRCSW system. The two introduced connectors performed well in transferring normal and tangential stress, according to the strain response and deformation results. The PC wall having bolted steel connection showed superior bearing capacity to that of the specimen with spiral hoop connection as the former connection could provide direct and reliable stress transmission. However, the spiral hoop connection could provide enough bond strength before the specimen cracked, of which the stress transferring is indirect, and it requires that the postcast concrete is well compacted to obtain excellent bond strength.

(4) In the two-story specimens, the cracks were mainly observed at the lower wall panel as the floor slab inhibited the cracks from propagating upward. This manifests that the base wall in multistory or high-rise building should be properly designed for resisting lateral force.

(5) Experiments showed that the adopted lap splicing connection in boundary area of two-story specimens could not provide seismic resistance sufficiently, especially when the specimen was imposed by a severe displacement drift. The lap splice bar fractured as the cyclic loading proceeded, leading to a joint opening at the tension side and concrete crushing at the compression side, thus bringing a brittle loss of bearing capacity. This suggests that lap connection at the boundary area needs to be strengthened for the flexural dominated wall.

(6) The predicted hysteric curves obtained by the numerical analysis are in good agreement with the test results. The proposed numerical models dealing with the bond-slip and shear-slip relationship were shown to reproduce satisfactory force-displacement response of tested specimens. The numerical research work provides a valuable tool for the design and analysis in the application of SRCSW system.

\section{Data Availability}

All data during this study are available from the corresponding author upon request.

\section{Conflicts of Interest}

The authors declare that they have no conflicts of interest.

\section{Acknowledgments}

This work was financially sponsored by the National Science Foundation of China (Grant no. 51578225). The authors wish to express their sincere gratitude to the sponsors.

\section{References}

[1] X. Chong, L. Xie, X. Ye, Q. Jiang, and D. Wang, "Experimental study and numerical model calibration of full-scale superimposed reinforced concrete walls with $I$-shaped cross sections," Advances in Structural Engineering, vol. 19, no. 12, pp. 1902-1916, 2016.

[2] M. J. N. Priestley, "Overview of PRESSS research program," PCI Journal, vol. 36, no. 4, pp. 50-57, 1991.

[3] M. J. N. Priestley, S. Sritharan, J. R. Conley, and S. Stefano Pampanin, "Preliminary results and conclusions from the PRESSS five-story precast concrete test building," PCI Journal, vol. 44, no. 6, pp. 42-67, 1999.

[4] Y. C. Kurama, "Seismic design of unbonded post-tensioned precast concrete walls with supplemental viscous damping," Structural Journal, vol. 97, no. 4, pp. 648-658, 2000.

[5] B. J. Smith, Y. C. Kurama, and M. J. McGinnis, "Behavior of precast concrete shear walls for seismic regions: comparison of hybrid and emulative specimens," Journal of Structural Engineering, vol. 139, no. 11, pp. 1917-1927, 2013.

[6] S.-M. Kang, O.-J. Kim, and H.-G. Park, "Cyclic loading test for emulative precast concrete walls with partially reduced rebar section," Engineering Structures, vol. 56, pp. 1645-1657, 2013.

[7] T. Guo, L. Wang, Z. Xu, and Y. Hao, "Experimental and numerical investigation of jointed self-centering concrete walls with friction connectors," Engineering Structures, vol. 161, pp. 192-206, 2018.

[8] K. M. Twigden and R. S. Henry, "Shake table testing of unbonded post-tensioned concrete walls with and without additional energy dissipation," Soil Dynamics and Earthquake Engineering, vol. 119, pp. 375-389, 2019.

[9] G. Xu and A. Li, "Seismic performance and design approach of unbonded post-tensioned precast sandwich wall structures with friction devices," Engineering Structures, vol. 204, p. 110037, 2020.

[10] C. Xiong, M. Chu, J. Liu, and Z. Sun, "Shear behavior of precast concrete wall structure based on two-way hollow-core precast panels," Engineering Structures, vol. 176, pp. 74-89, 2018.

[11] H.-N. Li, Y.-C. Tang, C. Li, and L.-M. Wang, "Experimental and numerical investigations on seismic behavior of hybrid braced precast concrete shear walls," Engineering Structures, vol. 198, Article ID 109560, 2019.

[12] M. F. Wang, T. Q. Zou, and Z. H. Wang, "A superimposed reinforced concrete shear wall with concealed steel plate 
bracings," Patent Office of the People's Republic of China, Beijing, China, ZL 201510006656.9, 2015.

[13] M. F. Wang and T. Q. Zou, "Experimental study on seismic behavior of precast composite shear wall with concealed bracing," Journal of Hunan University (Natural Sciences), vol. 44, no. 01, pp. 54-64, 2017, in Chinese.

[14] G. Toniolo and A. Colombo, "Precast concrete structures: the lessons learned from the L'Aquila earthquake," Structural Concrete, vol. 13, no. 2, pp. 73-83, 2012.

[15] SESOC Interim Design Guidance, Design of Conventional Structural Systems Following the Canterbury Earthquakes, Structural Engineering Society of New Zealand, New Zealand, 2013.

[16] X. Chong, L. Xie, X. Ye, Q. Jiang, and D. Wang, "Experimental study on the seismic performance of superimposed RC shear walls with enhanced horizontal joints," Journal of Earthquake Engineering, vol. 23, no. 1-2, pp. 1-17, 2017.

[17] K. A. Soudki, S. H. Rizkalla, and B. Leblanc, "Horizontal connections for precast concrete shear walls subjected to cyclic deformations Part 1: mild steel connections," PCI Journal, vol. 40, no. 4, pp. 78-96, 1995.

[18] I. N. Psycharis, I. M. Kalyviotis, and H. P. Mouzakis, "Experimental investigation of the response of precast concrete cladding panels with integrated connections under monotonic and cyclic loading," Engineering Structures, vol. 159, pp. 75-88, 2018.

[19] Q. Han, D. Wang, Y. Zhang, W. Tao, and Y. Zhu, "Experimental investigation and simplified stiffness degradation model of precast concrete shear wall with steel connectors," Engineering Structures, vol. 220, Article ID 110943, 2020.

[20] J. Sun, H. Qiu, Y. Lu, and H. Jiang, "Experimental study of lateral load behavior of $H$-shaped precast reinforced concrete shear walls with bolted steel connections," The Structural Design of Tall and Special Buildings, vol. 28, no. 15, Article ID e1663, 2019.

[21] J. Sun, H. Qiu, and H. Jiang, "Experimental study and associated mechanism analysis of horizontal bolted connections involved in a precast concrete shear wall system," Structural Concrete, vol. 20, no. 1, pp. 282-295, 2019.

[22] S. D. Shen, P. Pan, Q. S. Miao, W. F. Li, and R. H. Gong, "Test and analysis of reinforced concrete (RC) precast shear wall assembled using steel shear key (SSK)," Earthquake Engineering \& Structural Dynamics, vol. 48, no. 14, pp. 1595-1612, 2019.

[23] Y.-Y. Peng, J.-R. Qian, and Y.-H. Wang, "Cyclic performance of precast concrete shear walls with a mortar-sleeve connection for longitudinal steel bars," Materials and Structures, vol. 49, no. 6, pp. 2455-2469, 2016.

[24] D. Wu, S. Liang, M. Shen, Z. Guo, X. Zhu, and C. Sun, "Experimental estimation of seismic properties of new precast shear wall spatial structure model," Engineering Structures, vol. 183, pp. 319-339, 2019.

[25] P. Seifi, R. S. Henry, and J. M. Ingham, "In-plane cyclic testing of precast concrete wall panels with grouted metal duct base connections," Engineering Structures, vol. 184, pp. 85-98, 2019.

[26] N. Tullini and F. Minghini, "Grouted sleeve connections used in precast reinforced concrete construction - experimental investigation of a column-to-column joint," Engineering Structures, vol. 127, pp. 784-803, 2016.

[27] M. J. Ameli, D. N. Brown, J. E. Parks, and C. P. Pantelides, "Seismic column-to-footing connections using grouted splice sleeves," ACI Structural Journal, vol. 113, no. 5, pp. 1021-1030, 2016.
[28] F. Xu, K. Wang, S. Wang, W. Li, W. Liu, and D. Du, "Experimental bond behavior of deformed rebars in half-grouted sleeve connections with insufficient grouting defect," Construction and Building Materials, vol. 185, pp. 264-274, 2018.

[29] S. J. A. Hosseini and A. B. A. Rahman, "Effects of spiral confinement to the bond behavior of deformed reinforcement bars subjected to axial tension," Engineering Structures, vol. 112, pp. 1-13, 2016.

[30] S. J. A. Hosseini, A. B. A. Rahman, M. H. Osman, A. Saim, and A. Adnan, "Bond behavior of spirally confined splice of deformed bars in grout," Construction and Building Materials, vol. 80, pp. 180-194, 2015.

[31] GB 50017-2017, Standard for Design of Steel Structures, China Architecture and Building Press, Beijing, China, 2017, in Chinese.

[32] GB 50010-2010, Code for Design of Concrete Structures, China Architecture and Building Press, Beijing, China, 2010, in Chinese.

[33] R. Park, "Evaluation of ductility of structures and structural assemblages from laboratory testing," Bulletin of the new Zealand Society for Earthquake Engineering, vol. 22, no. 3, pp. 155-166, 1989.

[34] GB 5011-2010, Code for Seismic Design of Buildings, China Architecture and Building Press, Beijing, China, 2016, in Chinese.

[35] M. Wu, X. Liu, H. Liu, and X. Du, "Seismic performance of precast short-leg shear wall using a grouting sleeve connection," Engineering Structures, vol. 208, Article ID 110338, 2020.

[36] F. Mckenna, G. L. Fenves, and M. H. Scott, Open System for Earthquake Engineering Simulation, University of California, Berkeley, CA, USA, 2000, http://opensees.berkeley.edu.

[37] M. Palermo and T. Trombetti, "Experimentally-validated modelling of thin RC sandwich walls subjected to seismic loads," Engineering Structures, vol. 119, no. 15, pp. 95-109, 2016.

[38] X. Lu, X. Lu, H. Guan, and L. Ye, "Collapse simulation of reinforced concrete high-rise building induced by extreme earthquakes," Earthquake Engineering \& Structural Dynamics, vol. 42, no. 5, pp. 705-723, 2013.

[39] B. Wang, H. Jiang, and X. Lu, "Seismic performance of steel plate reinforced concrete shear wall and its application in China Mainland," Journal of Constructional Steel Research, vol. 131, pp. 132-143, 2017.

[40] J. Zhao, D. Petersen, and Z. Lin, "Behavior and design of castin-place anchors under simulated seismic loading," NEESAnchor Final Report, University of Wisconsin, Madison, WI, USA, 2013.

[41] J. Zhao and S. Sritharan, "Modeling of strain penetration effects in fiber-based analysis of reinforced concrete structures," ACI Structural Journal, vol. 104, no. 2, pp. 133-141, 2007.

[42] I. N. Psycharis and H. P. Mouzakis, "Shear resistance of pinned connections of precast members to monotonic and cyclic loading," Engineering Structures, vol. 41, pp. 413-427, 2012. 